\title{
Early to Adopt and Early to Discontinue: The Impact of Self- Perceived and Actual IT-Knowledge on Technology Use Behaviors of end Users
}

\author{
Rohit Aggarwal \\ University of Utah \\ David Kryscynski \\ Brigham Young University, dk@byu.edu \\ Vishal Midha \\ Illinois State University \\ Harpeet Singh \\ University of Texas at Dallas \\ Follow this and additional works at: https://scholarsarchive.byu.edu/facpub \\ Part of the Management Information Systems Commons
}

\section{Original Publication Citation}

Aggarwal, R., Kryscynski, D., Midha, V., \& Singh, H. 2015. Early to Adopt and Early to Discontinue: the impact of self-perceived and actual IT-knowledge on technology use behaviors of end users. Information Systems Research. 26 (1): 127-144.

\section{BYU ScholarsArchive Citation}

Aggarwal, Rohit; Kryscynski, David; Midha, Vishal; and Singh, Harpeet, "Early to Adopt and Early to Discontinue: The Impact of Self-Perceived and Actual IT-Knowledge on Technology Use Behaviors of end Users" (2015). Faculty Publications. 1978.

https://scholarsarchive.byu.edu/facpub/1978

This Peer-Reviewed Article is brought to you for free and open access by BYU ScholarsArchive. It has been accepted for inclusion in Faculty Publications by an authorized administrator of BYU ScholarsArchive. For more information, please contact ellen_amatangelo@byu.edu. 
Early to Adopt and Early to Discontinue: the impact of self-perceived and actual IT-knowledge on technology use behaviors of end users

\author{
Rohit Aggarwal \\ David Eccles School of Business \\ University of Utah \\ Salt Lake City, Utah 84112 \\ rohit.aggarwal@business.utah.edu \\ David Kryscynski \\ Marriott School of Management \\ Brigham Young University \\ Provo, Utah 84602 \\ dk@byu.edu \\ Vishal Midha \\ College of Business \\ Illinois State University \\ Normal, Illinois 61790 \\ vmidha@ilstu.edu \\ Harpreet Singh \\ Naveen Jindal School of Management \\ University of Texas at Dallas \\ Richardson, Texas 75080 \\ harpreet@utdallas.edu
}




\title{
Early to Adopt and Early to Discontinue: the impact of self-perceived and actual IT-knowledge on technology use behaviors of end users
}

\begin{abstract}
For organizations to achieve the benefits of new IT systems their users must adopt and then actually use these new systems. Recent models help to articulate the potentially different explanations for why some users will adopt and then continue using new technologies, but these models have not explicitly incorporated IT-knowledge. This is particularly important in contexts where the user base may be non-IT professionals - i.e. the users may vary substantially in their basic IT-knowledge. We draw upon psychology to argue that that in situations where there is wide variance in actual IT-knowledge there will often exist U relationship between actual and self-perceived IT-knowledge such that the least knowledgeable believe themselves to be highly knowledgeable. We then draw upon individual level adoption theories to argue that users with high self-perceived IT-knowledge will be more likely to adopt new technologies and do so faster. We also draw upon individual level continuance theories to argue that users with low actual IT-knowledge will be more likely to discontinue using new technologies and do so faster. We test our expectations using a proprietary data set of 225 sales professionals in a large Indian pharmaceutical company that is testing a new CRM system. We find strong support for our hypotheses.
\end{abstract}

Tags: IT Knowledge, non-IT professionals, Adoption, Continuance, Econometric analysis, Healthcare, Pharma, CRM, SaaS, Cloud computing, Self-assessment 


\section{Early to Adopt and Early to Discontinue: the impact of self-perceived and actual IT-knowledge on technology use behaviors of non-IT professionals}

There are at least two noticeable trends in research exploring the importance of individual users for the successful implementation of new organization level IT systems. First, for organizations to realize the performance benefits from their new IT systems, the individual users of those systems must adopt and then actually use the new technology (Jasperson et al. 2005; Venkatesh et al. 2003). The importance of individual users for the success of organization level IT implementation has led to substantial research exploring the factors that explain adoption (Davis 1989; Davis et al. 1989) and continuance (Bhattacherjee 2001; Jasperson et al. 2005; Venkatesh et al. 2003) at the individual level of analysis. These studies suggest that pre-adoption factors such as the perceived usefulness and perceived ease-ofuse drive user's adoption intentions and actual adoption behaviors. After adoption, however, these perceptions are confirmed (or not) in the process of actually using the technology and, accordingly, users may experience varied levels of satisfaction with the new technology. In short, models predicting the initial adoption behavior are driven primarily by the user's initial perceptions of the technology while models predicting subsequent continuance behaviors are driven by the user's actual experience with the technology. Thus, understanding both initial user perceptions as well as actual user experiences becomes critical for explaining whether users adopt and continually use new IT systems.

Second, while historical work exploring the implementation of new IT systems has focused on the ITknowledge of IT professionals, recent research has emphasized the importance of IT-knowledge for nonIT professionals as well (Bassellier et al. 2003; Bassellier et al. 2001) - i.e. the IT-knowledge of end users. IT-knowledge of end users is conceptualized as how well individuals "understand fundamental IT concepts [and] how well informed they are about IT in their organization” (Bassellier et al. 2003). As information technology becomes more ubiquitous within organizations, a larger percentage of workers need to consistently engage with new technologies and systems. Accordingly, the success or failure of implementing IT systems more fully relies on the ability of the broad user base to effectively adopt and 
utilize new technologies. In sum, this body of work suggests that individuals with higher IT-knowledge will be more likely to adopt new IT systems and more likely to continue using the new technology.

Despite the growing acknowledgment of the importance of IT-knowledge for the implementation of IT systems, especially among end users, extant theories of user level adoption and continuance only implicitly incorporate IT-knowledge. Explicitly incorporating user IT-knowledge is especially important given the observation that adoption behaviors depend on initial user perceptions (Venkatesh and Davis 2000; Venkatesh et al. 2003) and continuance behaviors depend on actual user experiences (Bhattacherjee 2001; Bhattacherjee and Barfar 2011; Bhattacherjee and Premkumar 2004). Specifically, user selfperceptions of IT-knowledge may be more predictive of adoption behaviors than actual IT-knowledge because self-perceptions drive initial evaluations. In contrast, user actual IT-knowledge may be more predictive of continuance behaviors because actual knowledge will dictate the quality of experience with the technology more than self-perceived IT-knowledge. This distinction may not be important in contexts where self-perceptions of IT-knowledge monotonically and predictably increase with actual ITknowledge - e.g. research contexts focused on IT professionals with universally high IT-knowledge. However, we may observe fundamentally different adoption and continuance behaviors from users at different ends of the IT-knowledge spectrum in contexts where self-perceived IT-knowledge does not monotonically increase with actual IT-knowledge. As we shall see, this non-monotonic relationship is especially likely when studying end users who vary substantially in their IT-knowledge.

We explore the importance of end user IT-knowledge for user level theories of adoption and continuance through the following research question: Do self-perceived and actual IT-knowledge have different effects on technology adoption and continuance behaviors for end users? We begin by arguing that end users vary substantially in their IT-knowledge and that this wide variance makes them subject to the Dunning-Kruger effect - i.e. the least and most knowledgeable actors have the highest selfperceptions of their own knowledge (Kruger and Dunning 1999, 2002). We then draw upon individual level adoption theories to argue that users with higher self-perceived IT-knowledge are more likely to adopt new IT systems and also adopt faster than those with lower self-perceived knowledge. We also 
draw upon individual level continuance theories to argue that users with lower actual IT-knowledge are less likely to continue using a new IT system and will also discontinue use sooner than users with higher actual IT-knowledge. These arguments lead to the conclusion that those who have the lowest levels of ITknowledge are most likely to adopt technology quickly because they anticipate being able to use the new technology effectively, but they are also the most likely to discontinue the technology quickly because their low IT-knowledge prevents them from realizing expected benefits.

We find support for our expectations using unique and proprietary data from the implementation of a software-as-a-service (SaaS) based customer relationship management (CRM) system at a large Indian Pharmaceutical company. We measure the self-perceived and actual IT-knowledge of 225 randomly selected sales representatives (i.e. the primary non-IT professional users of the CRM) and observe their fully optional adoption and discontinuance behaviors of the CRM. As expected, we find a U-shaped relationship between self-perceived and actual IT-knowledge among these sales representatives. Also as predicted, we find that workers with higher self-perceived IT-knowledge were more likely to adopt the CRM and did so sooner and workers with lower actual IT-knowledge were more likely to discontinue using the technology and did so sooner.

Accordingly we make at least three important contributions. First, we demonstrate the importance of explicitly incorporating both actual and perceived IT-knowledge into models of actual adoption and continuance volitional decisions. While perceived IT-knowledge may be critical for initial adoption behaviors, actual IT-knowledge may be more important for explaining continuance behaviors. Second, we demonstrate that the actual and perceived IT-knowledge may differ, especially in contexts where there are wide ranges of actual IT-knowledge. Thus, carefully attending to the differences between actual and selfperceived IT-knowledge may be especially important when studying end users. Third, since attending to actual IT-knowledge may be especially important when dealing with end users, we provide a practical instrument that organizations may leverage in their efforts to assess the actual IT-knowledge of their end users. 


\section{Theoretical Background}

To show why it is important to integrate insights from research on IT-knowledge of end users into models of individual level technology adoption and continuance it is first useful to articulate the unique contributions of each of these literatures to our collective understanding of how and why IT systems can be successfully implemented in organizations.

\section{User Level Theories of Technology Adoption and Continuance}

While many factors explain and predict organization level implementation outcomes, one of the most important factors is the extent to which individual users adopt and actually use new technology (Jasperson et al. 2005). The potential benefits of a new IT system can never be realized if users do not actually put the system to use in their regular work activities (Bhattacherjee 2001; Devaraj and Kohli 2003; Venkatesh and Davis 2000; Venkatesh et al. 2003). Davis’s (1989) original articulation of the Technology Acceptance Model (TAM) began a stream research examining the many factors that affect the extent to which individual users accept new technology and, therefore, the likelihood that they will adopt the new technology. He suggested the dual importance of perceived usefulness of the technology, or the extent to which the user can expect benefits from the technology, and the perceived ease-of-use of the technology, or how difficult it would be to actually realize the potential benefits from the technology (Davis 1989; Venkatesh and Davis 2000). The higher the expected benefits and the lower the difficulty of using the technology, the more likely the individual user will accept and subsequently adopt the new technology.

Through multiple studies (see Venkatesh et al. (2003) for a critical review) Davis’s original model has been validated and extended to include additional factors such as social influence, facilitating conditions, age, expertise, voluntariness of use, and so forth. In sum, individual users are more likely to intend to use and then actually adopt new technology when they expect high benefits from the technology, when the technology seems relatively easy to use, when important others want the individual to use the technology, and when the individual believes that the organization has sufficient technical 
infrastructure to support the system. Venkatesh et al. (2003) pull these insights together to develop the Unified Theory of Acceptance and Use of Technology (UTAUT).

It is also important to note that the body of research supporting the UTAUT largely seeks to explain the individual user's initial intentions to adopt the new technology. When explaining individual intentions it may be more useful to examine individuals' perceptions of reality rather than the objective reality (March and Simon 1958). For the purpose of initial decision making, individual perceptions likely correlate with but may be separate from the objective reality (March 1994). Accordingly, theories explaining user intentions to adopt technologies rely almost exclusively on user initial perceptions of themselves, their contexts and the technology. Consider, for example, the effort expectancy for a new technology. Venkatesh et al. (2003) suggest that the perceived ease of use (Davis 1989; Davis et al. 1989) and complexity (Thompson et al. 1991) both represent the extent to which the user believes that engaging with the new technology will require effort. As the perceived required effort increases, users' intentions to adopt decrease. Since effort expectancy is essentially another way of describing the user's self-efficacy towards the specific technology in question (Davis 1989; Venkatesh et al. 2003), it is helpful to note that Bandura's (1982) self-efficacy theory is specifically formulated to address the gap between an individual's actual knowledge and the individual's expected action. Bandura's key argument is that the individual's opinion of him/herself mediates the effect of that person's actual knowledge on actual behavioral outcomes. Thus, people with low self-perceived knowledge generally perform worse than people with high self-perceived knowledge, even when holding constant their actual knowledge. Accordingly, the individual's higher self-perceived IT-knowledge likely decreases the effort expectancy which, in turn, increases the likelihood of adoption. This simplified model summarizing the connections between users’ self-perceived IT-knowledge and adoption likelihood is shown in Figure 1 below.

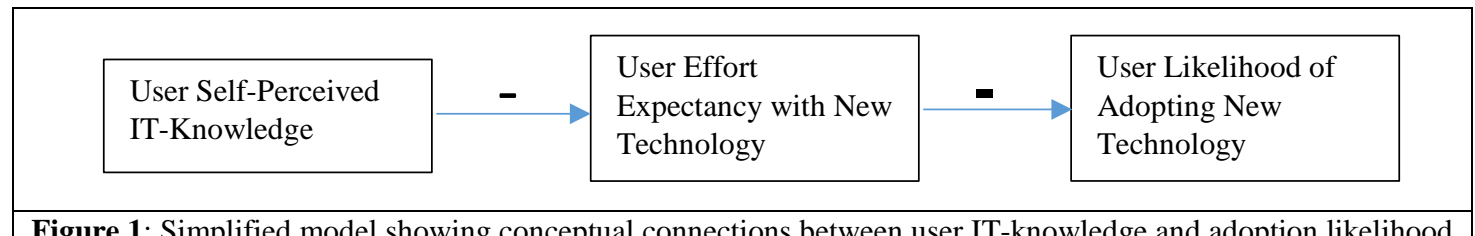

Figure 1: Simplified model showing conceptual connections between user IT-knowledge and adoption likelihood 
The problem with effort expectancy, however, is that research suggests that it is far more important for initial technology adoption than for continued use of technology (Agarwal and Prasad 1997; Davis 1989; Thompson et al. 1991; Thompson et al. 1994; Venkatesh et al. 2003). Specifically, empirical evidence shows that effort expectancy is predictive of user adoption intentions in initial time periods, but its predictive power wanes in subsequent time periods. Bhattacherjee (2001) addresses this concern directly in his technology continuance model, where continuance describes the user's continued use of the technology post adoption. He argues that once users begin to use the new technology their original expectations are either confirmed or disconfirmed leading to various levels of satisfaction with the new technology (Bhattacherjee 2001; Bhattacherjee and Barfar 2011; Bhattacherjee and Premkumar 2004). In other words, models predicting the continued use of technology rely upon the user's actual experience in the context of the user's initial expectations. The importance of the actual user experience has been validated in a number of empirical studies predicting the user's intention to continue using technology (Hong et al. 2011; Limayem et al. 2007 ; Lin et al. 2012; Zhao and Lu 2012; Zhou 2013; Zhou et al. 2012) .

Just as IT-knowledge affects the likelihood of adoption by decreasing the user's effort expectancy of the new technology, IT-knowledge also likely affects the user's continued use of technology by increasing the likelihood that the expected benefits will be realized, or confirmed, and the likelihood that the user will be satisfied with the technology. The more IT-knowledge the user has, the greater the ease of engaging with the new technology and actually leveraging the new technology to achieve desired outcomes. Thus, higher IT-knowledge likely leads to higher confirmation of benefits and satisfaction with the technology, which likely leads to higher continuance. A simplified model illustrating these conceptual connections is shown below in Figure 2. While we will develop the logic underlying these connections in detail in the sections that follow, it is important to note that our discussion of how IT-knowledge impacts continuance behaviors emphasizes actual IT-knowledge - i.e. actual IT-knowledge likely has a stronger impact on users' experience with technology than their self-perceived IT-knowledge. Thus, while self- 
perceived IT-knowledge seems critical for predicting adoption, actual IT-knowledge seems critical for predicting continuance.

\begin{tabular}{|c|c|c|c|c|}
\hline User Actual IT-Knowledge & + & $\begin{array}{l}\text { User Confirmed Benefits } \\
\text { and Satisfaction }\end{array}$ & $\stackrel{+}{\longrightarrow}$ & $\begin{array}{l}\text { User Likelihood of Continuing } \\
\text { to use Technology }\end{array}$ \\
\hline
\end{tabular}

Figure 2: Simplified model showing conceptual connections between user IT-knowledge and continuance likelihood

\section{IT-Knowledge of End Users}

The insight from the prior section that self-perceived IT-knowledge likely drives adoption behaviors while actual IT-knowledge likely drives continuance behaviors is particularly useful in contexts where self-perceived and actual IT-knowledge are not highly correlated. In contexts where they are highly correlated we can implicitly assume that self-perceived IT-knowledge positively impacts both adoption and continuance behaviors per the models described above. In contexts where they are not highly correlated, however, then there is the potential for some users to be high in self-perceived IT-knowledge but low in actual IT-knowledge. According to the theories reviewed above, these users may be very quick to adopt new IT systems because of their high self-perceived IT-knowledge, but they may also be likely to discontinue using the systems quickly because of their low actual IT-knowledge. Given the wide range of IT-knowledge likely among non-IT professionals, we suspect that this may be particularly relevant for adoption and continuance behaviors of end users.

Before we discuss the importance of IT-knowledge of end users further, however, it is important to clearly define what we mean by IT-knowledge. As mentioned in the introduction, IT-knowledge of end users is conceptualized as how well individuals "understand fundamental IT concepts [and] how well informed they are about IT in their organization.” (Bassellier et al., 2003: 320) Compared to the ITknowledge of the typical IT-professional, this knowledge might be considered quite basic. Bassellier and colleagues (2001) break IT-knowledge into five dimensions - (1) technology, (2) applications, (3) system development, (4) management of IT, and (5) access to IT knowledge. In addition to these five dimensions, related research also suggests a sixth dimension that captures the individual's knowledge of IT security 
(D'Arcy et al. 2009; Puhakainen and Siponen 2010; Spears and Barki 2010). To stay consistent with these models of IT-knowledge for non-IT professionals, then, we adopt these six dimensions of IT-knowledge (shown below in table 1).

Table 1: The six dimensions of IT-knowledge for non-IT professionals

\begin{tabular}{|l|l|l|}
\hline Component & Description & Source \\
\hline Technology & $\begin{array}{l}\text { Refers to understanding of the basic } \\
\text { components of IT and the awareness of } \\
\text { emerging technologies }\end{array}$ & $\begin{array}{l}\text { Bassellier et al. (2001); Nelson (1991); } \\
\text { Kollmann et al. (2009); Lee et al. (1995); Trauth } \\
\text { et al. (1993) }\end{array}$ \\
\hline Applications & $\begin{array}{l}\text { Refers to the ways that IT is used or could be } \\
\text { used to achieve goals }\end{array}$ & $\begin{array}{l}\text { Bassellier et al. (2001); Nelson (1991); } \\
\text { Kollmann et al. (2009); Lee et al. (1995); Trauth } \\
\text { et al. (1993) }\end{array}$ \\
\hline $\begin{array}{l}\text { Systems } \\
\text { development }\end{array}$ & $\begin{array}{l}\text { Refers to understanding of development } \\
\text { methods used to build a system in order to } \\
\text { understand the potential benefits, and } \\
\text { limitations of IT }\end{array}$ & $\begin{array}{l}\text { Bassellier et al. (2001); Brown et al. (2011); } \\
\text { Kollmann et al. (2009); Trauth et al. (1993) }\end{array}$ \\
\hline $\begin{array}{l}\text { Security } \\
\text { of IT }\end{array}$ & $\begin{array}{l}\text { Refers to the awareness of common security } \\
\text { threats and available defense mechanisms }\end{array}$ & $\begin{array}{l}\text { Puhakainen and Siponen (2010); D'Arcy et al. } \\
\text { (2009); Spears and Barki (2010) }\end{array}$ \\
\hline $\begin{array}{l}\text { Access to IT } \\
\text { Knowledge }\end{array}$ & $\begin{array}{l}\text { Kefers to activities such as vision and goal } \\
\text { of progress }\end{array}$ & $\begin{array}{l}\text { Bassellier et al. (2001); Silver et al. (1995); } \\
\text { Nelson (1991); Lee et al. (1995) }\end{array}$ \\
\hline
\end{tabular}

Extant research suggests that IT-knowledge of non-IT professionals is becoming more important in organizations because so much of organizational life is now mediated through IT systems (Kaarst-Brown 2005). In other words, most organization members are now users of IT systems in some way. Scholars have found that organizations experience more successful IT system implementations when enough of their users have at least the basic level of IT-knowledge described previously (Attewell 1992; Ko et al. 2005; Yoon et al. 1995). This basic IT-knowledge provides users with a foundation that allows them to gain more context-specific knowledge that will allow them to successfully use the new systems. Thus, their basic IT-knowledge will make new IT systems seem easier to use and learn (Jesitus 1997; Paas and Merriënboer 1994; Scheer and Habermann 2000; Wu and Wang 2007). Given the growing importance of end users of technology in organizations, it seems critical to explore the adoption and continuance behaviors of these users in order to better understand the conditions under which organization level implementation efforts are successful. 


\section{Theory Development}

Having established the importance of IT-knowledge in theories of individual adoption and continuance behaviors as well as the growing importance of end users, we now turn our attention to developing our hypotheses. Our first argument is that self-perceived IT-knowledge among end users will have a U relationship with actual IT-knowledge. We next argue that users with higher self-perceived ITknowledge will be more likely to adopt new IT systems and will also adopt those systems faster than users lower in self-perceived knowledge. Finally, we argue that users with lower actual IT-knowledge will be more likely to discontinue new IT-systems and will also discontinue use more quickly than users with higher actual IT-knowledge.

\section{The U-Relationship between Self-Perceived and Actual IT-Knowledge}

Psychologists studying individual self-assessments have found that in some contexts the individuals who are the least capable are also the people who over-assess their abilities the most (Kruger and Dunning 1999, 2002). This is typically called the Dunning-Kruger effect and it captures the idea that the people lowest in ability do not know enough to know and understand how little they know. As people become more knowledgeable and competent, they become better able to evaluate how much they do and do not know about certain topics. In a series of studies Kruger and Dunning (1999) show that the students who have the lowest levels of skills and abilities in areas such as logic, humor and grammar drastically over-estimate their own skills. The authors also find that improving participants' skills also improves their ability to assess themselves accurately. These findings have been verified in a number of contexts both in the real world as well as in the laboratory (Ehrlinger et al. 2008). Thus, in certain contexts, self-perceived ability seems to have a U relationship with actual ability.

While psychologists have found a U relationship between self-perceived and actual ability in contexts such as logic, humor and grammar, this relationship may also hold in other contexts. Prior studies have focused on specific knowledge domains where study participants displayed wide variance and examined the relationship between self-perceived and actual ability in those specific contexts. Prior work, however, 
focuses primarily on student populations and knowledge domains that may not be directly applicable to skills required in the workplace. We propose that this general U relationship will also hold when applied to the specific domain of IT-knowledge of end users. End users likely vary substantially in their ITknowledge. Some of these professionals may have IT training while others may feel overwhelmed by technology. These are professionals hired to perform job functions such as sales, marketing, design, human resources, and so forth. Given the educational and training backgrounds required for these nontechnical jobs it is not reasonable to expect all of these professionals to have general IT knowledge. We thus generally expect to find a broad distribution of actual IT-knowledge among non-IT professionals within organizations such that some have very high and others very low levels of general IT-knowledge.

Since we expect a wide range in general IT-knowledge among end users, then we also expect to find a U-relationship between self-perceived and actual IT-knowledge per the Dunning-Kruger effect described above. Thus, when end users have high levels of IT-knowledge they will be able to accurately assess their own level of knowledge because they know enough about IT to know what they do and do not know. In contrast, those with low levels of IT-knowledge will not be able to accurately assess their own level of knowledge because they do not know enough about IT to know what they do and do not know. Accordingly, they are likely to over-assess their own IT-knowledge when given an opportunity. We thus hypothesize:

H1: There is a U-relationship between self-perceived and actual IT-knowledge of end users such that self-perceived IT-knowledge decreases as actual IT-knowledge increases to a minimum selfassessment point, and then self-perceived IT-knowledge increase as actual IT-knowledge increases after the minimum point.

\section{The Impact of Self-Perceived IT-Knowledge on Adoption Behaviors}

According to hypothesis 1, those end users who are lowest in their IT-knowledge may also be most likely to over-assess their own IT-knowledge and, therefore, be very likely to adopt new IT systems. Individuals are more likely to believe that a certain technology will be easy to use if they believe that their 
own IT-knowledge is high (Bandura 2000). Bandura (2000) suggests that individuals' self-perceptions of their knowledge and abilities will directly affect how they view engaging with technology. If they believe that they are skilled and knowledgeable then they will believe that a new technology is easy to use precisely because their knowledge will allow them to master and use the new technology. Thus, higher self-perceived knowledge leads to higher perceptions of ease of use for new IT systems.

As reviewed above, individuals are more likely to adopt new technologies when they perceive that the new technologies are relatively easy to use (Dickerson and Gentry 1983; Hirschman 1980). Webster and Martocchio (1992) indicate that individuals become more comfortable with IT systems as their perceived level of effort needed to interact with those systems decreases. In a similar vein, Venkatesh and Davis (1996) suggest that the individuals who perceive high ease of use are more likely have positive perceptions of IT systems and more likely to engage with those systems. One of the most robust findings in research exploring intentions to adopt new technologies is that intentions to adopt and subsequent likelihood of adoption increase as the perceived ease of use increases. We thus expect that the likelihood of a non-IT professional adopting a new IT-system increases as that professional's self-perceived ITknowledge increases. Formally:

H2a: As an end user's self-perceived IT-knowledge increases that professional's likelihood of adopting a new IT system also increases.

In addition to self-perceived IT-knowledge increasing the likelihood of end user adoption, higher selfperceived IT-knowledge may also increase the speed of adoption by those users. Generally, when individuals consider adopting a new process or technology that they have not worked with previously, they seek additional information to assist them in deciding whether or not to adopt. Their desire to seek more information is a function of their self-perceived knowledge related to the new process or technology (Bransford 1979; Glenberg et al. 1982). The more they think they know, the less likely they are to seek out more information prior to making a decision to adopt the new technology. 
Applying this logic to the present context, when end users believe they have high IT-knowledge they are less likely to seek out additional information related to a new technology before adoption. In contrast, those who believe that they lack IT-knowledge may be more likely to gather additional information before proceeding with an adoption decision. These individuals may also perceive lower ease of use from the new technology given their low self-assessments and, therefore, they may wait to see how others experience the new technology before adopting themselves McFadden and Train (1996). Support for this logic comes from extant studies that find that the time to make IT related decisions increases as the perceived ease of use decreases (Kiesler 1966; Pollay 1970; Wiedenbeck 1985). Therefore, we expect that end users with high self-perceived IT-knowledge will adopt new IT systems quickly because they do not need to take the time to investigate those new systems further prior to adoption. Those with low selfperceived IT-knowledge will adopt new systems more slowly because they will want to take time to gain additional information and learn from the experiences of others. Thus:

H2b: As an end user's self-perceived IT-knowledge increases the time between being introduced to the new technology and adopting the technology decreases.

\section{The Impact of Actual IT-Knowledge on Continuance Behaviors}

Combining the insights from H1, H2a and H2b suggests that the people most likely to adopt new IT systems, and those who will adopt new IT systems most quickly are those who are either very high or very low in actual IT-knowledge. In other words, when end users can choose whether or not and when to adopt new systems, the professionals who adopt and do so quickly will be bi-modal in their IT-knowledge distribution - i.e. they will be both the most and least knowledgeable. If persistence and continued use of technology also depends on initial perceptions of own IT-knowledge, then this might not be concerning for organizations because these users will adopt early and persist. But, as reviewed previously, users’ actual experiences tend to have a greater impact on continued use than initial perceptions (Bhattacherjee 2001; Bhattacherjee and Barfar 2011; Bhattacherjee and Premkumar 2004; Karahanna et al. 1999). Thus, 
to understand the importance of both the most and least knowledgeable adopting quickly, we also need to understand the impact of actual knowledge on continuance behaviors.

When users adopt new IT systems they do so because they believe the new technology will deliver high perceived benefits and be relatively easy to use (Davis 1989; Venkatesh et al. 2003) . Once the users start to use the technology then they experience either confirmation or disconfirmation of the expectations that led them to adopt. Specifically, if the new system is more difficult to use than anticipated, then users will experience less payback per unit effort than they anticipated initially. When the required effort is more than the expected effort, individuals tend to demonstrate negative reactions such as anxiety or burnout (Basowitz et al. 1955; Jackson et al. 1986; Levi 1972), lower performance, and lower satisfaction (Kahn et al. 1964; Kaufmann and Beehr 1989; Lazarus and Folkman 1984). These users are more likely to discontinue using the new technology because their expectations were not confirmed and, therefore, their real experiences lead to dissatisfaction with the technology (Bhattacherjee 2001; Bhattacherjee and Barfar 2011; Bhattacherjee and Premkumar 2004).

In contrast, users who are high in IT-knowledge may be better able to evaluate the ease of use for a new technology. Scholars have found, for example, that experts are better able to accurately predict the effort required to successfully complete a software project (Mukhopadhyay et al. 1992; Vicinanza et al. 1991). It seems likely, then, that higher knowledge may also increase a user's ability to assess how much effort may be required to use a new technology. These users may adopt the technology quickly, as argued above, but are also likely to continue using the technology because their more realistic expectations are confirmed after beginning to use the technology. Thus, we expect the probability of continuance (discontinuance) to increase (decrease) as the user's actual IT-knowledge increases. Formally:

H3a: As an end user's actual IT-knowledge increases the likelihood of continuance (discontinuance) increases (decreases).

Additionally, users need to use and apply their actual IT-knowledge immediately when adopting new technologies. It is also likely that the IT-knowledge is most critical in the first stages of technology 
adoption when the individual is first learning how to use the new technology. This means that the experience of confirmation and/or disconfirmation of expected ease of use and expected benefits likely occurs very quickly after adopting and starting to use the technology. Users whose expectations are confirmed and who experience satisfaction will continue using the technology, ceteris paribus, and users whose expectations are not confirmed and who are dissatisfied will likely discontinue use very quickly. We thus expect that the time from adoption to discontinuance of a new technology increases (decreases) as the user's IT-knowledge increases (decreases). Formally:

H3b: As an end user's actual IT-knowledge increases (decreases) the time between adopting and discontinuing the technology increases (decreases).

Taken together, these hypotheses suggest that the most likely users to adopt a new technology quickly are those who are both very high and very low in actual technical competence. However, those high in actual IT-knowledge are likely to persist with the new technology while those low in actual IT-knowledge are likely to discontinue use quickly. Thus, those who are low in actual IT-knowledge are both early to adopt as well as early to discontinue.

\section{Data}

The ideal setting to test our theory is one where end users have an opportunity to adopt a new IT system of their own volition so that we can observe their initial adoption decisions as well as any discontinuance outcomes. Ideally we would observe users’ actual and self-perceived IT-knowledge to explore the relationship between self-perceived and actual knowledge as well as test the effects of actual and perceived IT-knowledge on adoption and discontinuance behaviors. Additionally, ideal data would hold constant organizational affiliation and context in order to explore the independent effects of ITknowledge on adoption and continuance behaviors.

We identify such a setting in the introduction of a customer relationship management (CRM) system for medical representatives (MRs) at an Indian pharmaceutical company (iPharma). The Indian 
pharmaceutical industry is ranked third in terms of the volume of sale of pharmaceuticals worldwide, and is increasingly competing with developed countries for global market share. The total market size for the Indian pharmaceutical industry is expected to grow from $\$ 12.6$ billion (USD) in 2009 to $\$ 55$ billion by 2020 (Bhadoria et al. 2010). Despite being such a large market, the Indian pharmaceutical industry is a highly fragmented industry, with roughly 250-300 organized companies and roughly 20,000 unorganized companies (Bhangale 2008). The top ten pharmaceutical companies account in total for less than $30 \%$ of industry sales, indicating the highly competitive nature of this industry. The sales in the pharmaceutical industry depend almost entirely on the efforts of the medical representatives. MRs provide information about drugs to physicians and encourage physicians to prescribe their drugs to patients. Since the relationship between MRs and physicians plays a significant role in whether the physicians prescribe drugs from the MRs’ company, the pharmaceutical companies have started exploring how to improve these relationships. MRs traditionally cover many physicians and, as a consequence, do not always carefully document all interactions with all physicians. This means that the MRs and the pharmaceutical companies often lack consistent and comprehensive data on their relationships with physicians.

The pharmaceutical company investigated in this study, called iPharma to maintain the anonymity of the company, uses MRs similarly to most companies in the industry. iPharma’s chief marketing officer (CMO) wanted to ascertain the company’s readiness to transition to a software-as-a-service (SaaS)-based CRM tool. The CMO did not know whether iPharma’s medical representatives had sufficient ITknowledge to effectively adopt and utilize such a tool and decided to conduct a phased investigation to determine whether the MRs were prepared. Two hundred twenty-five medical representatives (MRs) were randomly picked and invited to attend an information session for a SaaS-based CRM. Four of these invited MRs could not make it to the information session. In the information session, the CRM vendor illustrated various features and presented advantages of the CRM service. At the end of the presentation, the vendor offered a three-month trial period to the attending MRs. Participation in the trial was completely voluntary, and the participating MRs could discontinue the service at any time. Before the vendor's presentation, the MRs took an IT knowledge quiz that evaluated their self-perceived and actual 
IT-knowledge. After the vendor's presentation we observed if and when MRs adopted and then discontinued use of the CRM.

\section{Measures}

Independent Variables: The key independent variables for the present study are the actual and selfperceived IT-knowledge of medical representatives. To assess the actual IT-knowledge of MRs we developed an objective quiz with multiple choice questions and clear right and wrong answers. The quiz score provides our objective measure of the MRs' actual IT-knowledge. After taking the quiz the MRs then indicate their expected score on the quiz (Ehrlinger et al. 2008; Kruger and Dunning 1999). Their projected scores provides our measure of the MRs self-perceived IT-knowledge.

We developed the quiz based on the six knowledge dimensions discussed in the theory review section above. We started with the five dimensions developed by Bassellier and colleagues (2003): technology, applications, system development, management of IT and access to IT knowledge. While Bassellier and colleagues (2003) developed survey items to measure self-perceived IT-knowledge in each of these areas, we modified their items and created objective quiz questions rather than subjective ratings. For example, one of their measures for knowledge of technologies is "what is your general knowledge of multimedia?” The participant responds on a Likert type scale to indicate his or her self-assessment of general multimedia knowledge. We developed three objective measures to test actual multimedia knowledge as a subset of knowledge of technologies. One of our questions is "For viewing multimedia, and streaming video and audio, is the most widely used plugin in a web browser or on supported mobile devices: (a) Adobe Flash Player, (b) Windows Player, (c) Youtube, (d) Internet explorer.” We created similar objective measures to map to the other subjective measures Bassellier and colleagues (2003) developed. Since this was part of the CMO's efforts to assess the readiness of the MR workforce for the CRM system, the CMO has input into the design and length of the survey. Together with iPharma representatives we selected quiz items that simultaneously measured knowledge dimensions particularly relevant to this particular implementation while mapping carefully to the six domains of ITknowledge discussed previously. Accordingly, we were unable to fully map every item in the Bassellier et 
al. (2003) scale into our objective quiz. Where we had to eliminate items we tried to identify the items

that would be least relevant for individual success with this particular CRM. In addition to the five

dimensions identified, multiple IS faculty recommended that we draw upon the work of Puhakainen and

colleagues (2010) to include IT security. We also developed objective items to capture the extent to which

the MR has objective knowledge about IT security. We illustrate the mapping between these six

knowledge domains and this particular system implementation below in table 2. As shown in table 2, all

six domains seem particularly relevant for the user adoption and continued use of the SaaS based CRM.

Table 2: Mapping between IT-knowledge domains and use of SaaS based CRM system

\begin{tabular}{|c|c|c|}
\hline Component & Description & Phenomenological examples in the SaaS based CRM system for MRs \\
\hline Technology & $\begin{array}{l}\text { Refers to understanding of the } \\
\text { basic components of IT and } \\
\text { the awareness of emerging } \\
\text { technologies }\end{array}$ & $\begin{array}{l}\text { The CRM stores unsaved changes in RAM and requires a manual save in } \\
\text { order to upload changes to the system. MRs who lack a basic } \\
\text { understanding of information stored in RAM vs. the CRM system may } \\
\text { fail to successfully upload and save information. These MRs may } \\
\text { consistently lose data and assume that the problem is the CRM system } \\
\text { rather than user error. } \\
\text { To access the CRM system MRs need to use a VPN. MRs who do not } \\
\text { know how to effectively use and troubleshoot their VPNs may believe the } \\
\text { CRM system is unreliable rather than recognizing that the VPN } \\
\text { connection may be the problem. } \\
\text { MRs frequently show training videos to physicians as part of their sales } \\
\text { process. MRs need to understand the difference between streaming media } \\
\text { from a central location on the internal network and streaming media that } \\
\text { is stored on the local hard drive. MRs who do not understand the } \\
\text { importance of local media storage when they are off network may blame } \\
\text { the CRM system for their inability to show training videos. }\end{array}$ \\
\hline Applications & $\begin{array}{l}\text { Refers to the ways that IT is } \\
\text { used or could be used to } \\
\text { achieve goals }\end{array}$ & $\begin{array}{l}\text { The CRM system may send automated emails to physicians on behalf of } \\
\text { the MRs, but in some cases hospital systems may block emails from the } \\
\text { CRM mailer. MRs need to understand that the problem may due to the } \\
\text { hospital security rather than CRM failure. } \\
\text { MRs need to understand that scheduling appointments in the CRM does } \\
\text { not necessarily schedule appointments on physician's calendars because } \\
\text { their calendars are outside of the system. MRs need a basic understanding } \\
\text { of how calendar systems work. } \\
\text { The complex CRM system uses breadcrumbs to help MRs navigate the } \\
\text { different user interfaces. Basic knowledge of how these breadcrumbs } \\
\text { work can help the MRs quickly and effectively navigate the system. }\end{array}$ \\
\hline
\end{tabular}




\begin{tabular}{|c|c|c|}
\hline Component & Description & Phenomenological examples in the SaaS based CRM system for MRs \\
\hline $\begin{array}{l}\text { Systems } \\
\text { development }\end{array}$ & $\begin{array}{l}\text { Refers to understanding of } \\
\text { development methods used to } \\
\text { build a system in order to } \\
\text { understand the potential } \\
\text { benefits, and limitations of IT }\end{array}$ & $\begin{array}{l}\text { MRs who have richer knowledge in the process of developing IT systems } \\
\text { may be more understanding and patient with new features that are in beta. } \\
\text { They can give better feedback about failures to CRM provider and thus } \\
\text { accelerate their troubleshooting. } \\
\text { Understanding of requirement analysis may help MRs convey their } \\
\text { workflow better. They can get better guidance from the service provider } \\
\text { on how to customize their panel according to their needs. } \\
\text { Software companies are typically forced to prioritize feature requests for a } \\
\text { next release and thus not every request can get incorporated. MRs who } \\
\text { understand the system development process will be better able to set } \\
\text { realistic expectations for when their new feature requests may be } \\
\text { incorporated. }\end{array}$ \\
\hline Security & $\begin{array}{l}\text { Refers to the awareness of } \\
\text { common security threats and } \\
\text { available defense mechanisms }\end{array}$ & $\begin{array}{l}\text { MRs may not realize that a secure link is on https and not on http. They } \\
\text { may fail to open a website because they may miss "s" in https. } \\
\text { If MRs understand that a spyware may not be fixed/avoided with } \\
\text { antivirus, they may be more careful in opening attachments that they get } \\
\text { in emails. Then they may not blame the CRM provider for the spammy } \\
\text { popups in their browser. }\end{array}$ \\
\hline $\begin{array}{l}\text { Management } \\
\text { of IT }\end{array}$ & $\begin{array}{l}\text { Refers to activities such as } \\
\text { vision and goal setting, } \\
\text { allocation of resources, and } \\
\text { monitoring of progress }\end{array}$ & $\begin{array}{l}\text { Knowledge of company's vision of technology enabled data driven efforts } \\
\text { is likely to increase the inclination of MRs to adopt technologies that } \\
\text { support this vision. } \\
\text { Knowledge that modules such as inventory management are not } \\
\text { integrated into the service can avoid MRs to make faulty purchase orders } \\
\text { and delivery expectations. } \\
\text { Knowledge of IT budget can help in determining that how much external } \\
\text { help MRs can anticipate to receive with new systems. }\end{array}$ \\
\hline $\begin{array}{l}\text { Access to IT } \\
\text { Knowledge }\end{array}$ & $\begin{array}{l}\text { Knowing whom to contact to } \\
\text { get more information about IT }\end{array}$ & $\begin{array}{l}\text { On facing some technology challenge, if MRs know who to contact } \\
\text { depending on the nature of issue then this can save substantial of their } \\
\text { limited time; otherwise they would need to wait for someone in IT } \\
\text { helpdesk to identify the person for them. } \\
\text { If MRs know how to use existing knowledge-base at the company, then } \\
\text { they can quickly find answers to their common questions and do not have } \\
\text { to wait for other person to help them out. } \\
\text { Knowledge about people who are highly IT savvy and can help MRs to } \\
\text { get clearer understanding of the issue they are facing and what may be the } \\
\text { best approach to resolve it quickly. }\end{array}$ \\
\hline
\end{tabular}

To validate and improve our quiz items we first reached out to 16 CIOs who agreed that the quiz was appropriate for assessing the IT-knowledge of non-IT professionals. These CIOs have both deep ITknowledge themselves as well as a clear understanding of what basic IT-knowledge is required by non-IT professionals when adopting new IT systems. They were thus well positioned to evaluate whether the quiz would clearly measure the readiness of non-IT professionals to adopt and use a SaaS based CRM. We 
next recruited eight IS faculty members to participate in a card sorting exercise to ensure that the items sorted appropriately into the theoretical categories we intended (Cenfetelli et al. 2008). The card-sorting exercise resulted in average 90\% classification accuracy across the faculty members. This high classification accuracy suggests that the classification was satisfactory overall. We also received recommendations from these eight faculty members for improving the wording of the questions, and updated the questions accordingly. Lastly, we discussed the quiz in detail with five MRs in interviews that ranged from 60-90 minutes. We explored any difficulties with wording and made appropriate adjustments. After our extensive reviews with CIOs, IS faculty members and a sample of MRs we finalized the quiz with 46 items. These items are shown in the appendix. The MR's actual score out of a possible 46 correct answers indicates that MR's actual IT-knowledge.

We further validated our measurement approach by administering the quiz to 51 third-year undergraduate business school students. Out of these, 5 quizzes were deemed unusable and the remaining 46 quizzes were used to validate. ${ }^{1}$ To validate our measure of actual IT-knowledge we calculated correlations between students' grades in a Management Information Systems course and their quiz scores, and we found a statistically significant high correlation $(\rho=0.78$ and $p$-value $<0.000)$. Since the course grade is likely a strong proxy for the students’ basic IT-knowledge, this high correlation lends support to the validity of the actual IT-knowledge measure. To validate our measure of self-perceived IT-knowledge we created a subjective self-assessment based on the work of Bassellier et al. (2003) - i.e. we used existing instruments in the literature to measure student's self-perceived IT-knowledge. We correlated the students' scores on this self-assessment instrument with our measure of their self-perceived ITknowledge. The high correlation $(\rho=0.83$ and $p$-value $<0.000)$ between these two different measures of self-perceived IT-knowledge suggests that our approach accurately measures self-perceived ITknowledge.

\footnotetext{
${ }^{1}$ To validate the quiz, four of the six components were used. The other two components, management of IT and access to IT knowledge, were not used owing to iPharma's confidentiality issues.
} 
To test the reliability of measuring IT-knowledge with our quiz scores we used the split-half method (Bollen 1989). In the split-half method, a quiz is first divided into two parts and the correlation between the quiz score of the two halves is calculated. The correlation gives the reliability of each half of the quiz. The Spearman Brown Prophecy formula is then applied to the correlation to calculate the reliability of the full quiz, which is given by $(2 * \rho) /(1+\rho)$ where $\rho$ is the correlation between the quiz scores of the two halves. The split-half reliability for our quiz came out to be 0.835 , which is substantially higher than the threshold value of 0.7 (Bollen 1989) and indicates that the quiz is reliable.

Dependent Variables: The key dependent variables are the adoption of the CRM system, the time to adoption of the CRM system, the discontinuance of the CRM system and the time to discontinuance of the CRM system. The adoption of the CRM system was operationalized by a dummy variable, $\mathrm{y}_{\mathrm{i}}^{\mathrm{adopt}}$. This variable takes the value 1 if MR $i$ logs into his or her account at least one time after the initial training meeting, and takes the value 0 if he or she never logs in. A concern in relying on the first login is that a few individuals may never come back after logging in once. To account for such behavior, we also tested our models by operationalizing IT adoption as the $x^{\text {th }}$ login to one’s account, and ran models with different values of $x$. These extra analyses are discussed in detail in the robustness checks section. Most individuals who logged in once came back multiple times to use the system. Therefore, the results were qualitatively similar for considerably larger values of $x$.

The time to adoption of the CRM system was operationalized as the number of days between the CRM information session and the first user login. As mentioned above, we did multiple robustness checks for different ways to calculate the time to adoption. We measured the time taken as the number of days between the CRM information session and the $x^{\text {th }} \log$ in, for different values of $\mathrm{x}$. These additional analyses are also discussed in the robustness checks.

The discontinuance of the CRM system captured whether the MR wanted to continue using the CRM after the conclusion of the three month trial period offered by the software vendor. This variable was 
operationalized by a dummy variable, $\mathrm{y}_{\mathrm{i}}^{\text {discontinue }}$, which takes the value 1 if MR $i$ discontinues the CRM service account that he or she initiated at the start of the trial period, and takes the value 0 otherwise. MRs who did not initiate their account were not considered while examining discontinuance.

The time to discontinuance of the CRM system was operationalized as the number of days between adopting the CRM system by opening an account and logging in and the last login, conditional upon the user's decision to discontinue using the technology. Time to discontinuance is only calculated for those MRs who clearly indicate an intention to discontinue.

Control Variables: An exhaustive list of controls was added to avoid any possible confounding of the estimated influence of actual and perceived IT-knowledge on the key dependent variables. These factors include tendency to adopt new technologies, tendency to discontinue technologies, quality, IT education, age, company experience, industry experience, schooling, IT experience, number of clients, and non-IT knowledge.

To control for the MRs’ idiosyncratic characteristics (such as quality, tendency to adopt new technologies, and tendency to discontinue technologies), we gathered feedback from MRs' immediate supervisors. Supervisors reported their assessments of MRs’ quality, tendency to adopt new technologies, and tendency to discontinue new technologies on a scale of $1-10$, where 10 refers to the highest level and 1 refers to the lowest level. MRs’ IT experience was operationalized as their number of hours of interaction with IT per week. MRs were also asked to report the number of months of formal IT education and the number of years of schooling separately. The number of years worked in iPharma was used to measure company experience, whereas the number of years worked in the pharmaceutical industry was used to measure industry experience. We also controlled for MRs' age in years. To account for the influence of the workload handled by MRs, we added the control number of clients.

Lastly, it is natural to consider that individuals may be inherently oriented to wrongly assess their own knowledge across domains. Individuals who wrongly assess their IT knowledge may also wrongly assess their knowledge in other non-IT domains. In order to test such a possibility, we controlled for how 
assessments in the IT domain are affected by non-IT knowledge, specifically pharmaceutical knowledge.

MRs also took a pharmaceutical quiz, and their scores on this quiz served as a measure for non-IT

knowledge. The correlation matrix for all the variables is reported in Table 3 below.

Table 3: Correlation Matrix

\begin{tabular}{|c|c|c|c|c|c|c|c|c|c|c|c|c|c|c|c|c|c|c|}
\hline & & 1 & 2 & 3 & 4 & 5 & 6 & 7 & 8 & 9 & 10 & 11 & 12 & 13 & 14 & 15 & 16 & 17 \\
\hline 1 & Time to discontinue & 1.00 & & & & & & & & & & & & & & & & \\
\hline 2 & Decision to discontinue & -0.59 & 1.00 & & & & & & & & & & & & & & & \\
\hline 3 & Adoption decision & 0.42 & -0.14 & 1.00 & & & & & & & & & & & & & & \\
\hline 4 & Time to adopt & 0.42 & -0.16 & 0.78 & 1.00 & & & & & & & & & & & & & \\
\hline 5 & $\begin{array}{l}\text { Self-perceived IT- } \\
\text { knowledge }\end{array}$ & 0.10 & -0.03 & 0.45 & -0.03 & 1.00 & & & & & & & & & & & & \\
\hline 6 & Actual IT-knowledge & 0.60 & -0.52 & 0.03 & 0.01 & -0.01 & 1.00 & & & & & & & & & & & \\
\hline 7 & Quality & 0.61 & -0.24 & 0.38 & 0.52 & -0.03 & 0.18 & 1.00 & & & & & & & & & & \\
\hline 8 & Tendency to adopt & 0.18 & -0.08 & 0.31 & 0.17 & 0.16 & 0.03 & 0.13 & 1.00 & & & & & & & & & \\
\hline 9 & Tendency to discontinue & -0.38 & 0.35 & -0.07 & -0.07 & -0.05 & 0.00 & -0.10 & -0.12 & 1.00 & & & & & & & & \\
\hline 10 & Age & -0.11 & 0.33 & -0.10 & 0.04 & -0.28 & -0.08 & 0.04 & -0.13 & 0.03 & 1.00 & & & & & & & \\
\hline 11 & Company experience & 0.06 & 0.18 & -0.09 & 0.02 & -0.20 & 0.11 & 0.11 & 0.00 & -0.05 & 0.08 & 1.00 & & & & & & \\
\hline 12 & Industry experience & 0.16 & 0.03 & 0.00 & 0.10 & -0.16 & 0.11 & 0.19 & -0.01 & 0.00 & 0.02 & 0.72 & 1.00 & & & & & \\
\hline 13 & IT-experience & 0.15 & 0.05 & 0.18 & 0.09 & 0.02 & -0.06 & 0.12 & -0.01 & 0.00 & -0.09 & 0.06 & 0.04 & 1.00 & & & & \\
\hline 14 & IT-education & 0.48 & -0.22 & 0.30 & 0.34 & -0.12 & 0.15 & 0.25 & -0.02 & 0.00 & 0.02 & 0.10 & 0.25 & 0.04 & 1.00 & & & \\
\hline 15 & Years of schooling & 0.00 & 0.01 & 0.08 & 0.13 & -0.09 & -0.07 & 0.07 & 0.08 & 0.11 & 0.07 & 0.07 & 0.02 & 0.17 & 0.09 & 1.00 & & \\
\hline 16 & Domain-knowledge & 0.17 & -0.13 & 0.03 & 0.13 & -0.08 & 0.13 & 0.21 & 0.00 & -0.24 & -0.01 & 0.37 & 0.24 & -0.10 & 0.08 & 0.01 & 1.00 & \\
\hline 17 & Number of clients & 0.04 & -0.01 & -0.01 & 0.06 & -0.08 & -0.04 & 0.06 & 0.03 & -0.06 & 0.01 & 0.08 & 0.05 & 0.05 & 0.05 & 0.00 & 0.18 & 1.00 \\
\hline
\end{tabular}

\section{Models}

\section{The U-Relationship between Self-Perceived and Actual IT-Knowledge}

The general specification of the model is as follows:

$$
\text { SPITKnow }_{i}=\beta_{0}+\beta_{1} \text { AITKnow }_{i}+\beta_{2} \text { AITKnow }_{i}{ }_{i}+Z_{i} \eta^{\text {assess }}+\varepsilon_{i}{ }^{\text {assess }}
$$

where SPITKnow is $^{i^{\text {th }}}$ individual's self-perceived IT-knowledge; AITKnow $_{i}$ is the actual IT-

knowledge of the $i^{\text {th }}$ individual; $Z_{i}$ is the vector of control variables; and $\varepsilon_{i}{ }^{\text {assess }}$ is idiosyncratic error.

The results from the analysis are reported in Table 4 (Model 2).Conclusions about hypothesis 1:

Consistent with hypothesis 1, we find that actual IT-knowledge has a curvilinear relationship

with self-perceived IT-knowledge. The co-efficient of actual IT-knowledge is negative and

statistically significant $(-0.1481, p$-value $<0.01)$ whereas the co-efficient of square of actual IT-

knowledge is positive and statistically significant $(0.0621$, p-value $<0.01)$. The positive and

significant value of the square term indicates that the relationship between actual IT-knowledge 
and self-perceived IT-knowledge is not linear. Figure 3 plots the predicted value of selfperceived IT-knowledge at different values of actual IT-knowledge keeping all other independent variables at their mean value. Figure 3 shows that the predicted value of selfperceived IT-knowledge is highest at minimum value of actual IT-knowledge. As actual ITknowledge increases from its minimum value, self-perceived IT-knowledge decreases and reaches a minimum point when actual IT-knowledge is moderate. Self-perceived IT-knowledge subsequently increases with increase in actual IT-knowledge.

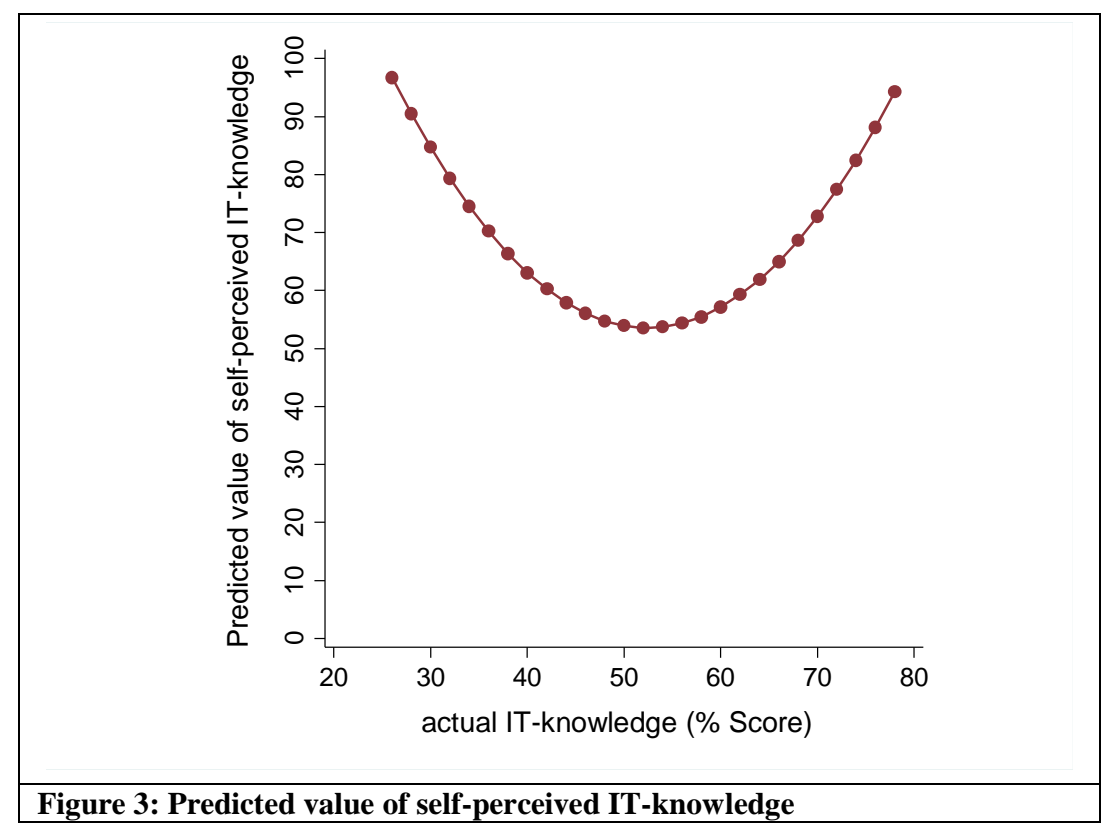

Table 4: Models for MRs’ self-perceived IT knowledge to test hypothesis 1 . Model 1 presents results with only control variables for self-perceived IT-knowledge. Model 2 (complete model) adds focal independent variables to model 1. Since, ITknowledge and square of IT-knowledge can be highly correlated; we followed the recommended method of mean centering ITknowledge before taking the square to reduce correlation to acceptable level (Gelman and Hill 2007).

\begin{tabular}{|c|c|c|}
\hline & \multicolumn{2}{|c|}{$\begin{array}{l}\text { Dependent Variable: Self- } \\
\text { perceived IT-knowledge }\end{array}$} \\
\hline & $\begin{array}{l}\text { Model 1- } \\
\text { Controls } \\
\text { Only }\end{array}$ & $\begin{array}{l}\text { Model 2- } \\
\text { Full model }\end{array}$ \\
\hline $\begin{array}{l}\text { Actual IT- } \\
\text { knowledge }\end{array}$ & & $\begin{array}{c}-0.1481 * * * \\
(0.0423)\end{array}$ \\
\hline $\begin{array}{l}\text { (Actual IT- }^{\text {(Anowledge) }}{ }^{2} \\
\text { know }\end{array}$ & & $\begin{array}{c}0.0621^{* * *} \\
(0.0026)\end{array}$ \\
\hline Quality & $\begin{array}{c}0.1691 \\
(0.6467)\end{array}$ & $\begin{array}{l}0.8670^{* *} \\
(0.3606)\end{array}$ \\
\hline $\begin{array}{l}\text { Tendency to take } \\
\text { initiatives }\end{array}$ & $\begin{array}{l}0.9673^{* *} \\
(0.4541)\end{array}$ & $\begin{array}{c}0.9912^{* * *} \\
(0.2829)\end{array}$ \\
\hline Age & $\begin{array}{c}-1.2819 * * * \\
(0.3409)\end{array}$ & $\begin{array}{c}-1.2935 * * * \\
(0.1984)\end{array}$ \\
\hline
\end{tabular}




\begin{tabular}{|c|c|c|} 
Company & -2.458 & $-1.7394 * *$ \\
experience & $(1.5509)$ & $(0.8103)$ \\
\hline Industry & -0.2116 & -0.2219 \\
experience & $(1.0151)$ & $(0.5618)$ \\
\hline \multirow{2}{*}{ IT-experience } & 0.3638 & 0.5255 \\
& $(0.8018)$ & $(0.4561)$ \\
\hline \multirow{2}{*}{ IT-education } & -0.2446 & $0.3611^{* * *}$ \\
& $(0.1798)$ & $(0.1114)$ \\
\hline Years of & -1.4031 & -0.3037 \\
schooling & $(1.4002)$ & $(0.7906)$ \\
\hline Domain- & -0.009 & 0.0003 \\
knowledge & $(0.1298)$ & $(0.0741)$ \\
\hline \multirow{2}{*}{ Number of clients } & -0.1414 & -0.0706 \\
& $(0.1362)$ & $(0.0785)$ \\
\hline Constant & $141.9972 * * *$ & $91.0141 * * *$ \\
& $(26.6367)$ & $(16.5235)$ \\
\hline $\mathrm{N}$ & 221 & 221 \\
\hline $\mathrm{R}^{2}$ & 0.4123 & 0.7196 \\
\hline
\end{tabular}

Note: Standard errors are in parentheses; ${ }^{* * *} \mathrm{p}<0.01,{ }^{* *} \mathrm{p}<0.05,{ }^{*} \mathrm{p}<0.1$.

\section{The Impact of Self-Perceived IT-Knowledge on Adoption Behaviors}

To investigate the influence of self-perceived IT-knowledge on an individual's decision to adopt a new IT system, we use the logit model. The general specification of the model is as follows:

$$
\begin{gathered}
P\left(\mathrm{y}_{\mathrm{i}}^{\text {adopt }}=1 \mid \text { SPITKnow }_{i}, \text { AITKnow }_{i}, \text { AITKnow }^{2}, Z_{i}\right) \\
=F\left(\alpha_{0}+\alpha_{1} \text { SPITKNow }_{i}+\alpha_{2} \text { AITKnow }_{i}+\alpha_{3} \text { AITKnow }_{i}{ }_{i}+Z_{i} \eta^{\text {adopt }}+\varepsilon_{i}{ }^{\text {adopt }}\right)
\end{gathered}
$$

where $P\left(\mathrm{y}_{\mathrm{i}}^{\text {adopt }}=1\right)$ is the probability that the $i^{\text {th }}$ individual will adopt the new CRM, $F($.$) is the logit$ function, and $\varepsilon_{i}{ }^{\text {adopt }}$ is idiosyncratic error. The results from the analysis are reported in Table 5 (Model 4).

The coefficient of SPITKnow $i$ is positive and significant $(0.0820, p<0.01)$, suggesting that an increase in self-perceived IT-knowledge positively and significantly increases the likelihood that an MR will adopt the new CRM. Accordingly, we find strong support for H2a.

To investigate the time to adoption we used the model with the following specification:

$$
\text { Time_adopt }_{i}=\gamma_{0}+\gamma_{1} \text { SPITKnow }_{i}+\gamma_{2} \text { AITKnow }_{i}+\gamma_{3} \text { AITKnow }_{i}{ }_{i}+Z_{i} \eta^{\text {time_adopt }}+\varepsilon_{i} \text { time_adopt }^{\text {tim }}
$$

where Time_adopt $t_{i}$ is the time between the training meeting and the initial login for the $i^{\text {th }}$ individual, and $\varepsilon_{i}{ }^{\text {time_adopt }}$ is idiosyncratic error. The results from the analysis are reported in Table 5 (Model 6). 
The coefficient of SPITKnow ${ }_{i}$ is negative and significant $(-0.0908, p<0.01)$, suggesting that higher self-perceived IT knowledge leads to lower time to adoption. Accordingly, we find strong support for H2b.

Table 5: Models for hypotheses 2a and 2b. Model 3 presents results with only control variables for adoption decision. Model 4 adds focal independent variables to model 3. Model 5 presents results of model with only control variables for the time to adopt. Model 6 adds focal independent variables to model 5. Since, actual IT-knowledge and square of actual IT-knowledge can be highly correlated; we followed the recommended method of mean centering actual IT-knowledge before taking the square to reduce correlation to acceptable level (Gelman and Hill 2007).

\begin{tabular}{|c|c|c|c|c|}
\hline & \multicolumn{2}{|c|}{$\begin{array}{c}\text { Dependent Variable: } \\
\text { Adoption decision }\end{array}$} & \multicolumn{2}{|c|}{$\begin{array}{c}\text { Dependent Variable: } \\
\text { Time to adopt }\end{array}$} \\
\hline & $\begin{array}{c}\text { Model 3- } \\
\text { Controls } \\
\text { Only }\end{array}$ & $\begin{array}{l}\text { Model 4- } \\
\text { Full model }\end{array}$ & $\begin{array}{c}\text { Model 5- } \\
\text { Controls } \\
\text { Only }\end{array}$ & $\begin{array}{l}\text { Model 6- } \\
\text { Full model }\end{array}$ \\
\hline $\begin{array}{l}\text { Self-perceived } \\
\text { IT-knowledge }\end{array}$ & & $\begin{array}{c}0.0820 * * * \\
(0.0308)\end{array}$ & & $\begin{array}{c}-0.0908^{* * *} \\
(0.0123)\end{array}$ \\
\hline $\begin{array}{l}\text { Actual IT- } \\
\text { knowledge }\end{array}$ & & $\begin{array}{l}-0.0024 \\
(0.0217)\end{array}$ & & $\begin{array}{c}0.002 \\
(0.0051)\end{array}$ \\
\hline $\begin{array}{l}\text { (Actual IT- } \\
\text { knowledge) }\end{array}$ & & $\begin{array}{l}0.0045^{* *} \\
(0.0022) \\
\end{array}$ & & $\begin{array}{c}-0.0018^{* *} \\
(0.0007) \\
\end{array}$ \\
\hline Quality & $\begin{array}{c}0.4570 * * * \\
(0.1076)\end{array}$ & $\begin{array}{c}0.8560 * * * \\
(0.1806)\end{array}$ & $\begin{array}{c}0.5051 * * * \\
(0.0912)\end{array}$ & $\begin{array}{c}0.1981 * * * \\
(0.0555)\end{array}$ \\
\hline $\begin{array}{c}\text { Tendency to } \\
\text { adopt }\end{array}$ & $\begin{array}{c}0.4483 * * * \\
(0.0968)\end{array}$ & $\begin{array}{c}0.4774 * * * \\
(0.1135)\end{array}$ & $\begin{array}{l}-0.0998 * \\
(0.0579)\end{array}$ & $\begin{array}{c}-0.1579 * * * \\
(0.0368)\end{array}$ \\
\hline Age & $\begin{array}{l}-0.0484 \\
(0.0623)\end{array}$ & $\begin{array}{l}-0.0309 \\
(0.0914)\end{array}$ & $\begin{array}{l}0.1074 * * \\
(0.0503)\end{array}$ & $\begin{array}{l}-0.0028 \\
(0.0289)\end{array}$ \\
\hline $\begin{array}{c}\text { Company } \\
\text { experience }\end{array}$ & $\begin{array}{c}-0.5621^{* *} \\
(0.2582)\end{array}$ & $\begin{array}{l}-0.2037 \\
(0.3493) \\
\end{array}$ & $\begin{array}{c}0.0146 \\
(0.2139) \\
\end{array}$ & $\begin{array}{c}0.0213 \\
(0.1094) \\
\end{array}$ \\
\hline $\begin{array}{c}\text { Industry } \\
\text { experience }\end{array}$ & $\begin{array}{c}0.0257 \\
(0.1531)\end{array}$ & $\begin{array}{l}-0.2602 \\
(0.2154)\end{array}$ & $\begin{array}{c}0.0641 \\
(0.1301)\end{array}$ & $\begin{array}{c}0.0168 \\
(0.0716)\end{array}$ \\
\hline IT-experience & $\begin{array}{l}0.3213 * * \\
(0.1301)\end{array}$ & $\begin{array}{c}0.4929 * * * \\
(0.1895)\end{array}$ & $\begin{array}{c}-0.095 \\
(0.1108) \\
\end{array}$ & $\begin{array}{c}-0.3014 * * * \\
(0.0630)\end{array}$ \\
\hline IT-education & $\begin{array}{c}0.1259 * * * \\
(0.0341)\end{array}$ & $\begin{array}{c}0.2634 * * * \\
(0.0611)\end{array}$ & $\begin{array}{c}0.0188 \\
(0.0221) \\
\end{array}$ & $\begin{array}{c}-0.0768^{* * *} \\
(0.0153) \\
\end{array}$ \\
\hline $\begin{array}{c}\text { Years of } \\
\text { schooling }\end{array}$ & $\begin{array}{c}0.0961 \\
(0.2280) \\
\end{array}$ & $\begin{array}{c}0.204 \\
(0.3025) \\
\end{array}$ & $\begin{array}{l}0.3258 * \\
(0.1733) \\
\end{array}$ & $\begin{array}{c}0.1212 \\
(0.0947) \\
\end{array}$ \\
\hline $\begin{array}{c}\text { Domain- } \\
\text { knowledge }\end{array}$ & $\begin{array}{c}0.0152 \\
(0.0226) \\
\end{array}$ & $\begin{array}{c}0.0026 \\
(0.0240) \\
\end{array}$ & $\begin{array}{c}0.0083 \\
(0.0173) \\
\end{array}$ & $\begin{array}{c}0.0069 \\
(0.0089) \\
\end{array}$ \\
\hline Number of clients & $\begin{array}{l}-0.0239 \\
(0.0242)\end{array}$ & $\begin{array}{l}-0.0072 \\
(0.0328)\end{array}$ & $\begin{array}{c}0.0185 \\
(0.0188)\end{array}$ & $\begin{array}{c}0.0003 \\
(0.0097)\end{array}$ \\
\hline Constant & $\begin{array}{l}-3.3097 \\
(4.6720)\end{array}$ & $\begin{array}{c}-15.9951^{* *} \\
(7.0081)\end{array}$ & $\begin{array}{c}-8.1200^{* * *} \\
(2.9851)\end{array}$ & $\begin{array}{c}10.6920 * * * \\
(2.0901)\end{array}$ \\
\hline $\mathrm{N}$ & 221 & 221 & 155 & 155 \\
\hline $\mathrm{R}^{2} /$ Log likelihood & -94.5129 & -63.3197 & 0.2982 & 0.7951 \\
\hline
\end{tabular}

Note: Standard errors are in parentheses; ${ }^{* * *} \mathrm{p}<0.01,{ }^{* *} \mathrm{p}<0.05,{ }^{*} \mathrm{p}<0.1$.

‡ Only 155 out of 221 MRs chose to adopt the CRM service.

\section{Relationship between IT-knowledge and adoption behavior}

The combined insights from H1, H2a and H2b suggests that the people most likely to adopt new IT systems, and those who will adopt new IT systems most quickly are those who are either very high or very low in actual IT-knowledge. To check whether our results support this insight we plotted predicted 
values of probability of adopting the CRM system and predicted value of time to adopt at different values of actual IT-knowledge in figure 3a and figure 3b respectively. Figure 3a and 3b shows that those with high actual IT-knowledge and low actual IT-knowledge are more likely to adopt the CRM system and will do so more quickly.

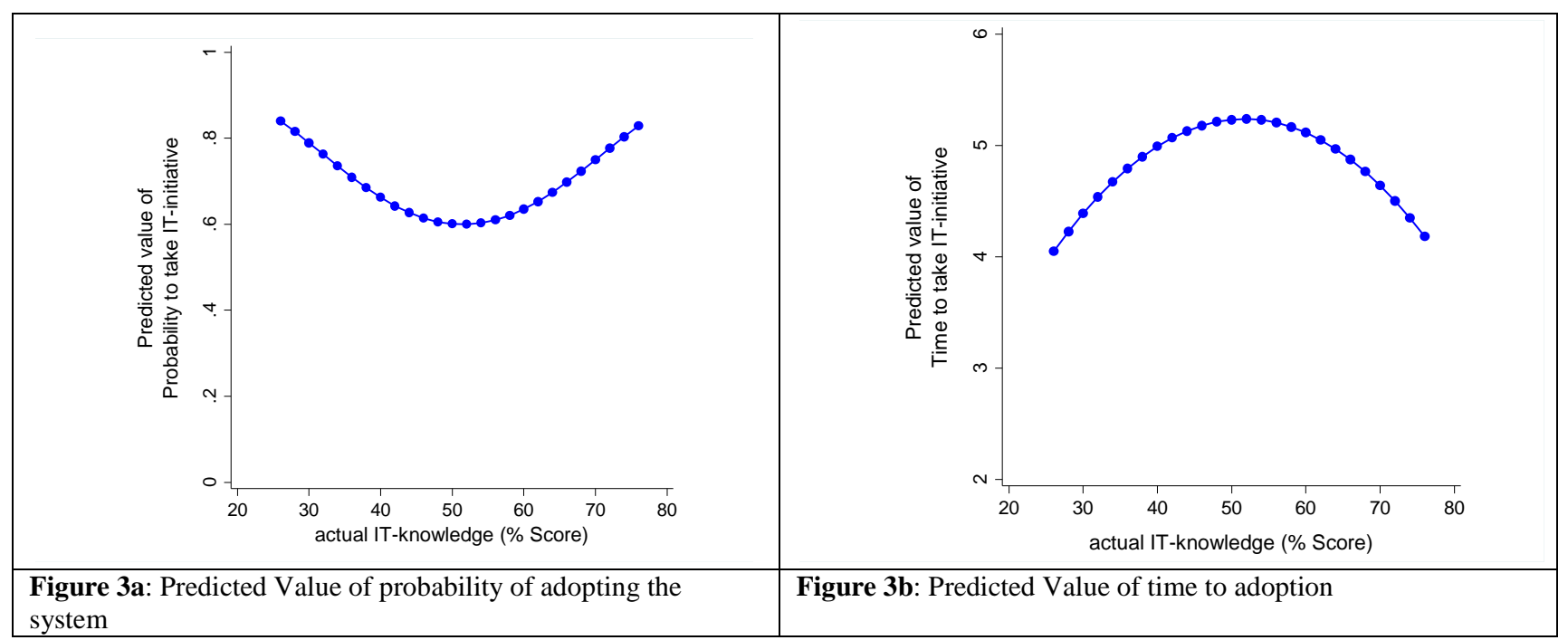

\section{The Impact of Actual IT-Knowledge on Continuance Behaviors}

To investigate the influence of actual IT-knowledge on an individual's decision to discontinue using the technology, we use the logit model. The general specification of the model is as follows:

$$
P\left(\mathrm{y}_{\mathrm{i}}^{\text {discontinue }}=1 \mid \text { AITKnow }_{i}, Z_{i}\right)=F\left(\delta_{0}+\delta_{1} \text { AITKnow }_{i}+Z_{i} \eta^{\text {discontinue }}+\varepsilon_{i}^{\text {discontinue }}\right)
$$

where $P\left(\mathrm{y}_{\mathrm{i}}^{\text {discontinue }}=1\right)$ is the probability that the $i^{\text {th }}$ individual will discontinue using the CRM;

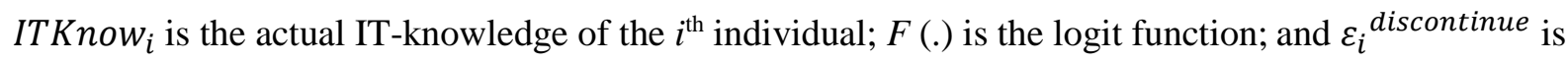
idiosyncratic error. The results from the analysis are reported in Table 6 (Model 8).

The coefficient of AITKnow $i$ is negative and significant $(-0.1949, p<0.01)$, suggesting that an increase in actual IT-knowledge decreases the probability of discontinuing use of the CRM. Thus, we see strong support for hypothesis 3a.

We investigate the time to discontinue the CRM system using the following model specification:

$$
\text { Time_discontinue }_{i}=\theta_{0}+\theta_{1} \text { AITKnow }_{i}+Z_{i} \eta^{\text {time_discontinue }}+\varepsilon_{i}{ }^{\text {time_dicontinue }}
$$


where Time_discontinue $_{i}$ is the time taken by the $i^{\text {th }}$ individual to discontinue use of the CRM, $\operatorname{AITKnow}_{i}$ is the actual IT-knowledge of the $i^{\text {th }}$ individual; and $\varepsilon_{i}{ }^{\text {time_discontinue }}$ is idiosyncratic error.

The results from the analysis are reported in Table 6 (Model 10).

The coefficient of AITKnow $i$ is positive and significant $(0.6617, p<0.01)$, suggesting that an increase in IT-knowledge increases the time to discontinuance for the CRM system. Accordingly, we find strong support for H3b.

Table 6: Models for hypotheses 3a and 3b. Model 7 presents results of model with only control variables for discontinuance decision. Model 8 adds focal independent variables to model 7. Model 9 presents results of model with only control variables for the time to discontinue. Model 10 adds focal independent variables to model 9.

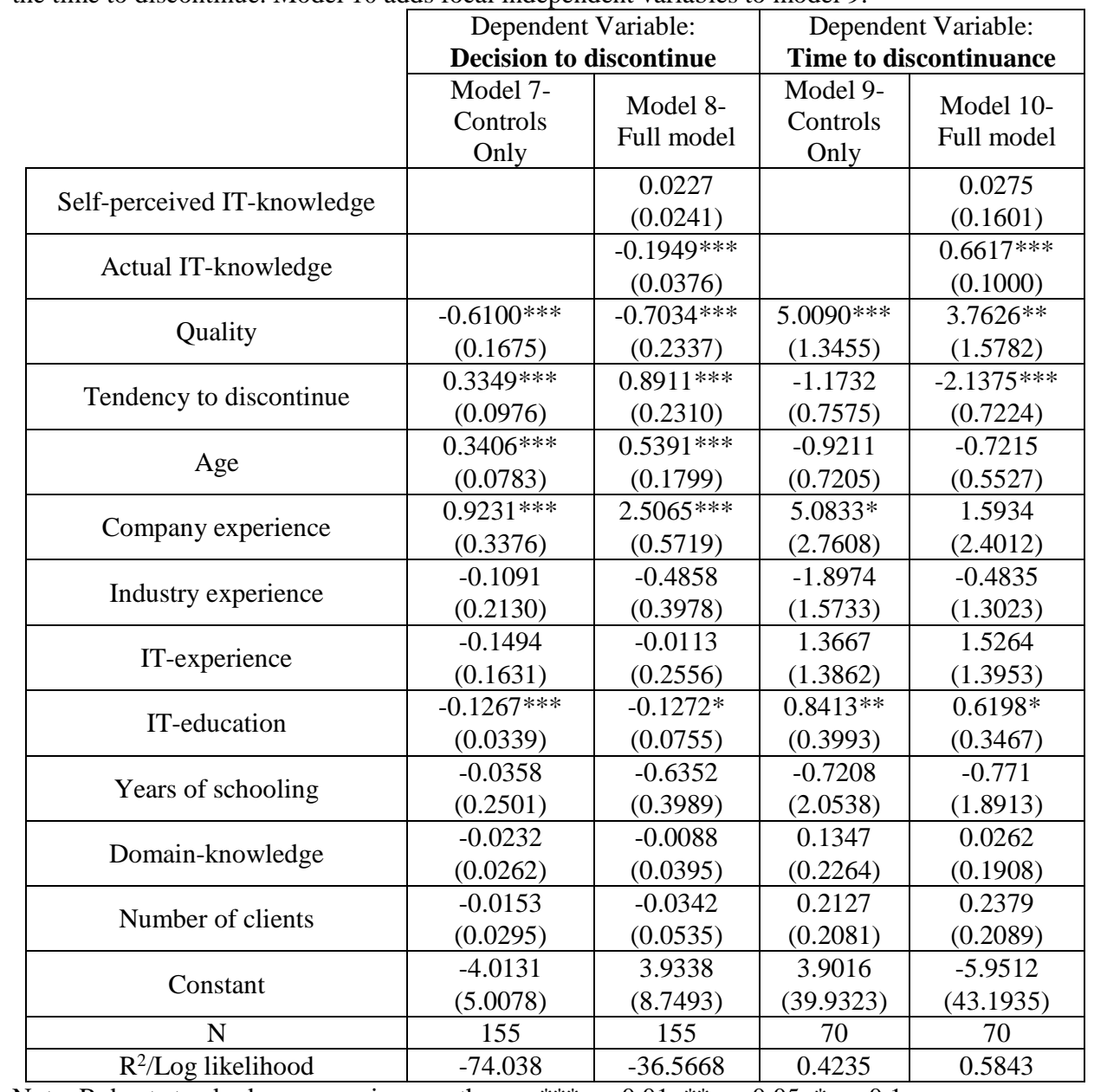

Note: Robust standard errors are in parentheses; ${ }^{* * *} \mathrm{p}<0.01,{ }^{* *} \mathrm{p}<0.05,{ }^{*} \mathrm{p}<0.1$

$\ddagger$ Only 70 out of 155 MRs chose to abandon the CRM service.

\section{Summary of results}

We find support for all hypotheses. To summarize, we find a strong U relationship between selfperceived and actual IT-knowledge. This suggests that those who are highest and lowest in actual IT- 
knowledge are most likely to believe that they have high IT-knowledge. We find that the likelihood of adopting the CRM system increases with individuals' self-perceived IT-knowledge: that is, individuals with high self-assessments of IT-knowledge are more likely to adopt a new IT system. We also find that those with higher self-perceived IT-knowledge adopt the new system faster. Similarly, those with higher actual IT-knowledge are less likely to discontinue using the new system and take longer to discontinue use. Taken together, our results show that those low in actual IT-knowledge are more likely to adopt the new system faster and more likely to discontinue the new system faster.

\section{Robustness Check}

Operationalization of decision to adopt: We have operationalized the decision to adopt the CRM systems as the activation of a CRM service account. A concern in relying on this measure is that individuals may not use the service after activating their accounts. To control for such behavior, we also tested the adoption decision model by operationalizing adoption as the $x^{\text {th }}$ login instead of the first login. We ran our model with four different values of $\mathrm{x}(2,3,4$, and 10). For example, when $\mathrm{x}$ is 3 , MRs who logged into their accounts twice or less were grouped with those who did not adopt. Similarly, when $\mathrm{x}$ is 3, the time to adopt equals the number of days between the CRM information session and the third login. The results for different values of $x$ for both adoption and time to adoption were qualitatively similar.

Quiz score reliability: To test the reliability of quiz scores, we use the split-half method (Bollen 1989). In the split-half method, the quiz is first divided into two parts. We also ran our empirical models using the scores from quiz halves separately for all models. Results from these split halves were qualitatively similar to the results from the total score, and this also supports the reliability of the quiz.

Measurement of IT-knowledge: It can be argued that some dimensions of our quiz like "system development”, “management of IT” and “access to IT” might not be very relevant for MRs. Therefore, we did an additional robustness check, where we excluded scores on "system development”, "management of IT” and "access to IT” from our aggregated scores to measure IT-knowledge. The results of these analyses are qualitatively similar to results reported in paper. 
Censoring of adoption decision: Because MRs were given a fixed three month window to decide whether or not to adopt, we do not face the kinds of censoring issues that are ordinarily present in adoption studies. Still, in the absence of the three-month window it is likely that some number of nonadopters would have eventually adopted. As a result, we decided to run a robustness check to see what would happen if non-adopters were all treated as if they were censored observations. Specifically we have used hazard models for the adoption decision and survival models for time to adoption decision. In the hazard models the focus is on event (adoption decision in our case) whereas in survival models the focus is on time to event. The results of this analysis are qualitatively similar to results reported in the paper.

\section{Discussion and Conclusions}

Successfully implementing a new IT system requires individual users to both adopt and then continuing to use the new technology. Our study contributes to research exploring individual adoption and continuance behaviors by explicitly incorporating both self-perceived and actual IT knowledge of individual users. We show that self-perceived knowledge predicts adoption behaviors while actual knowledge predicts continuance behaviors. Accordingly, our work helps to integrate the substantial body of adoption research (Venkatesh and Davis 2000; Venkatesh et al. 2003) with the growing body of continuance research (Bhattacherjee 2001; Bhattacherjee and Barfar 2011; Bhattacherjee and Premkumar 2004). Specifically, our research helps to explain why adoption and continuance behaviors cannot be treated identically. Our findings suggest that those who are fast to adopt may not always be the most likely to persist with new technologies, and our unique contribution is that at least a part of this difference may be explained by individual differences between self-perceived and actual IT-knowledge. This distinction may not be important in contexts where self-perceptions of IT-knowledge monotonically and predictably increase with actual IT-knowledge - e.g. research contexts focused on IT professionals with universally high IT-knowledge. However, we may observe fundamentally different adoption and continuance behaviors from users at different ends of the IT-knowledge spectrum in contexts where self- 
perceived IT-knowledge does not monotonically increase with actual IT-knowledge. We theoretically argued and empirically validated that the self-perceived IT-knowledge follows a U-shaped pattern, which is especially likely when studying end users who vary substantially in their IT-knowledge.

Beyond just demonstrating the differences between self-perceived and actual IT-knowledge of end users and their respective impacts on adoption and continuance behaviors, our study suggests an opportunity to examine a wider set of constructs commonly explored in technology adoption and usage research. Bandura's concept of self-efficacy (Bandura, 1982), for example, shows up frequently in technology adoption research (Venkatesh, Morris, Davis, \& Davis, 2003) because higher self-efficacy increases the probability of adoption. But, self-efficacy is a function of an individual's self-perceived competence. Our study suggests that in some situations self-efficacy may align well with actual competence and in other situations there may be an inverted $U$ relationship between actual competence and self-efficacy. Our findings, then suggest the need to carefully examine studies drawing upon concepts, such as self-efficacy, that rely heavily upon self-perceptions of competence. Specifically, we may need to carefully examine whether these studies effectively evaluate the coupling between selfperceived and actual competence. Thus, our study suggests an important boundary condition for theories leveraging concepts such as perceived usefulness, self-efficacy, perceived ease-of-use and so forth, to explain technology adoption and use. Specifically, these theories may hold when there is a tight coupling between self-perceived and actual competence, but they may not hold when self-perceived and actual competence are loosely coupled or follow the inverted $\mathrm{U}$ relationship we describe here.

In addition to these theoretical contributions, our study also provides a potential solution for companies searching for practical ways to assess the IT-knowledge of end users. The tool used in the present study allowed us to predict actual usage behaviors and reveal the differences between selfperceived and actual IT-Knowledge. In practice, this tool may allow companies to predict which users are most likely to adopt and continue to use new technologies.

This study also has implications for organizations that rely on their employees’ discretion to keep themselves abreast of the changing IT needs in their organizations. Many organizations expect their 
employees to self-select themselves into various IT training programs and be responsible for updating their necessary IT skills. Extant work suggests that a good portion of employees do not attend such IT training sessions (Thomson et al. 2001). It may be that many such employees lack IT knowledge and fail to realize their need for IT training. Organizations may be better off identifying those less knowledgeablein-IT and mandating that they attend IT training programs, rather than relying on employees' selfrealization.

Another potential application of our findings may be in explaining student enrollments in IT courses. Our results indicate that those less knowledgeable-in-IT tend to perceive themselves to possess high IT knowledge. Prior literature shows that individuals who assess themselves to possess high IT knowledge may perceive IT education as redundant and less valuable (Wood and Lynch Jr 2002). Thus, ironically, those less knowledgeable-in-IT—assessing themselves to possess high IT knowledge—may exhibit lower levels of interest in IT courses, when they are the ones who need to take such courses the most. Such disinterest may not only be adversely impacting the students' readiness for industry, but also be worsening the count of student enrollments in IT programs.

If individuals' lack of IT knowledge affects their own assessment, then it is highly plausible to conclude that individuals’ lack of IT knowledge may also affect their assessment of others' IT knowledge. One may expect those less knowledgeable-in-IT to fail in objectively ascertaining the IT knowledge of others. Others who are also less knowledgeable-in-IT, not knowing what they do not know, may sound confident and knowledgeable to individuals who are less knowledgeable-in-IT. In contrast, those who are highly knowledgeable-in-IT, better understanding the limits of their knowledge, may come across as less confident and less knowledgeable to individuals who are less knowledgeable-in-IT. Thus, it should be quite interesting to study how the interaction of individuals’ own IT knowledge and others’ IT knowledge shapes individuals' assessments of others. Considering this, the selection decisions of less-knowledgeable IT recruiters and managers become questionable. Those less-knowledgeable IT decision-makers, as opposed to the highly knowledgeable ones, may select a higher number of those less knowledgeable-inIT. A similarly problematic example could be the selection of CIOs. Often, top management teams 
without a strong IT background are involved in selecting CIOs. Such teams may systematically be failing to recognize a lack of IT knowledge among selected candidates. Future research is needed to more carefully explore these important issues in broader contexts than we have studied here. 


\section{References}

Agarwal, R., J. Prasad. 1997. The role of innovation characteristics and perceived voluntariness in the acceptance of information technologies. Decision Sciences 28(3) 557-582.

Attewell, P. 1992. Technology diffusion and organizational learning: the case of business computing. Organization Science 3(1) 1-19.

Bandura, A. 1982. Self-efficacy mechanism in human agency. American Psychologist 37(2) 122-147.

Bandura, A. 2000. Cultivate self-efficacy for personal and organizational effectiveness. E.A. Locke, ed. The Blackwell handbook of principles of organizational behavior. Blackwell, Oxford, 120-136.

Basowitz, H., H. Persky, S.J. Korchin, R.R. Grinker. 1955. Anxiety and stress. McGraw-Hill, New York.

Bassellier, G., I. Benbasat, B.H. Reich. 2003. The influence of business managers' IT competence on championing IT. Information Systems Research 14(4) 317-336.

Bassellier, G., B.H. Reich, I. Benbasat. 2001. Information technology competence of business managers: a definition and research model. Journal of Management Information Systems 17(4) 159-182.

Bhadoria, V., A. Bhajanka, K. Chakraborty, P. Mitra. 2010. India Pharma 2020: Propelling access and acceptance, realising true potential. McKinsey \& Company.

Bhangale, V. 2008. Pharma marketing in India: opportunities, challenges and the way forward. Journal of Medical Marketing 8(3) 205-210.

Bhattacherjee, A. 2001. Understanding information systems continuance: an expectation-confirmation model. MIS Quarterly 25(3) 351-370.

Bhattacherjee, A., A. Barfar. 2011. Information technology continuance research: current state and future directions. Asia Pacific Journal of Information Systems 21(2) 1-18.

Bhattacherjee, A., G. Premkumar. 2004. Understanding changes in belief and attitude toward information technology usage: a theoretical model and longitudinal test. MIS Quarterly 28(2) 229-254.

Bollen, K.A. 1989. Structural equations with latent variables. Wiley New York, New York.

Bransford, J.D. 1979. Human cognition: Learning, understanding and remembering. Wadsworth, Belmont, CA.

Brown, C.V., D.W. DeHayes, J.A. Hoffer, W.E. Martin, W.C. Perkins. 2011. Managing information technology, 7 ed. Prentice Hall.

Cenfetelli, R.T., I. Benbasat, S. Al-Natour. 2008. Addressing the what and how of online services: positioning supporting-services functionality and service quality for business-to-consumer success. Information Systems Research 19(2) 161-181.

D'Arcy, J., A. Hovav, D. Galletta. 2009. User awareness of security countermeasures and its impact on information systems misuse: a deterrence approach. Information Systems Research 20(1) 79-98. 
Davis, F.D. 1989. Perceived usefulness, perceived ease of use, and user acceptance of information technology. MIS Quarterly 13(3) 319-340.

Davis, F.D., R.P. Bagozzi, P.R. Warshaw. 1989. User acceptance of computer technology: a comparison of two theoretical models. Management Science 35(8) 982-1003.

Devaraj, S., R. Kohli. 2003. Performance impacts of information technology: is actual usage the missing link? Management Science 49(3) 273-289.

Dickerson, M.D., J.W. Gentry. 1983. Characteristics of adopters and non-adopters of home computers. Journal of Consumer Research 10(2) 225-235.

Ehrlinger, J., K. Johnson, M. Banner, D. Dunning, J. Kruger. 2008. Why the unskilled are unaware: further explorations of (absent) self-insight among the incompetent. Organizational Behavior and Human Decision Processes 105(1) 98-121.

Gelman, A., J. Hill. 2007. Data analysis using regression and multilevel/hierarchical models. Cambridge University Press, Cambridge, UK.

Glenberg, A.M., A.C. Wilkinson, W. Epstein. 1982. The illusion of knowing: failure in the selfassessment of comprehension. Memory \& Cognition 10(6) 597-602.

Hirschman, E.C. 1980. Innovativeness, novelty seeking, and consumer creativity. Journal of Consumer Research 7(3) 283-295.

Hong, W., J.Y.L. Thong, L.C. Chasalow, G. Dhillon. 2011. User acceptance of agile information systems: a model and empirical test. Journal of Management Information Systems 28(1) 235-272.

Jackson, S.E., R.L. Schwab, R.S. Schuler. 1986. Toward an understanding of the burnout phenomenon. Journal of Applied Psychology 71(4) 630-640.

Jasperson, J.S., P.E. Carter, R.W. Zmud. 2005. A comprehensive conceptualization of post-adoptive behaviors associated with information technology enabled work systems. MIS Quarterly 29(3) 525-557.

Jesitus, J. 1997. Broken promises? FoxMeyer's project was a disaster. Was the company too aggressive or was it misled? Industry Week 246(20) 31-36.

Kaarst-Brown, M.L. 2005. Understanding an organization's view of the CIO: the role of assumptions about IT. MIS Quarterly Executive 4(2) 287-301.

Kahn, R.L., D.M. Wolfe, R.P. Quinn, J.D. Snoek, R.A. Rosenthal. 1964. Organizational stress: studies in role conflict and ambiguity. Wiley, New York.

Karahanna, E., D.W. Straub, N.L. Chervany. 1999. Information technology adoption across time: a crosssectional comparison of pre-adoption and post-adoption beliefs. MIS Quarterly 23(2) 183-213.

Kaufmann, G.M., T.A. Beehr. 1989. Occupational stressors, individual strains, and social supports among police officers. Human Relations 42(2) 185-197.

Kiesler, C.A. 1966. Conflict and number of choice alternatives. Psychological Reports 18(2) 603-610. 
Ko, D.-G., L.J. Kirsch, W.R. King. 2005. Antecedents of knowledge transfer from consultants to clients in enterprise system implementations. MIS Quarterly 29(1) 59-85.

Kollmann, T., M. HäSel, N. Breugst. 2009. Competence of IT professionals in e-business venture teams: the effect of experience and expertise on preference structure. Journal of Management Information Systems 25(4) 51-79.

Kruger, J., D. Dunning. 1999. Unskilled and unaware of it: how difficulties in recognizing one's own incompetence lead to inflated self-assessments. Journal of Personality and Social Psychology 77(6) 11211134.

Kruger, J., D. Dunning. 2002. Unskilled and unaware-but why? A reply to Krueger and Mueller (2002). Journal of Personality and Social Psychology 82(2) 189-192.

Lazarus, R.S., S. Folkman. 1984. Stress, appraisal, and coping. Springer Publishing Company, New York, NY.

Lee, D.M.S., E.M. Trauth, D. Farwell. 1995. Critical skills and knowledge requirements of IS professionals: a joint academic/industry investigation. MIS Quarterly 19(3) 313-340.

Levi, L. 1972. Stress and distress in response to psychosocial stimuli. Laboratory and real life studies on sympathoadrenomedullary and related reactions. Pergamon Press, Oxford.

Limayem, M., S.G. Hirt, C.M.K. Cheung. 2007 How habit limits the predictive power of intention: the case of information systems continuance. MIS Quarterly 31(4) 705-737.

Lin, T.-C., S. Wu, J.S.-C. Hsu, Y.-C. Chou. 2012. The integration of value-based adoption and expectation-confirmation models: an example of IPTV continuance intention. Decision Support Systems 54(1) 63-75.

March, J.G. 1994. Primer on decision making: how decisions happen. The Free Press, New York, NY.

March, J.G., H.A. Simon. 1958. Organizations. John Wiley \& Sons, New York.

McFadden, D.L., K.E. Train. 1996. Consumers' evaluation of new products: learning from self and others. Journal of Political Economy 104(4) 683-703.

Mukhopadhyay, T., S.S. Vicinanza, M.J. Prietula. 1992. Examining the feasibility of a case-based reasoning model for software effort estimation. MIS Quarterly 16(2) 155-171.

Nelson, R.R. 1991. Educational needs as perceived by IS and end-user personnel: a survey of knowledge and skill requirements. MIS Quarterly 15(4) 503-525.

Paas, F.G.W.C., J.J.G.V. Merriënboer. 1994. Variability of worked examples and transfer of geometrical problem-solving skills: a cognitive-load approach. Journal of Educational Psychology 86(1) 122-133.

Pollay, R.W. 1970. A model of decision times in difficult decision situations. Psychological Review 77(4) 274-281.

Puhakainen, P., M. Siponen. 2010. Improving employees' compliance through information systems security training: an action research study. MIS Quarterly 34(4) 757-778. 
Scheer, A.-W., F. Habermann. 2000. Enterprise resource planning: making ERP a success. Communications of the ACM 43(4) 57-61.

Silver, M.S., M.L. Markus, C.M. Beath. 1995. The information technology interaction model: a foundation for the MBA core course. MIS Quarterly 19(3) 361-390.

Spears, J.L., H. Barki. 2010. User participation in information systems security risk management. MIS Quarterly 34(3) 503-522.

Thompson, R.L., C.A. Higgins, J.M. Howell. 1991. Personal computing: toward a conceptual model of utilization. MIS Quarterly 15(1) 125-143.

Thompson, R.L., C.A. Higgins, J.M. Howell. 1994. Influence of experience on personal computer utilization: testing a conceptual model. Journal of Management Information Systems 11(1) 167-187.

Thomson, A., C. Mabey, J. Storey, C. Gray, P. Iles. 2001. Changing patterns of management development. Blackwell, Oxford.

Trauth, E.M., D.W. Farwell, D. Lee. 1993. The IS expectation gap: industry expectations versus academic preparation. MIS Quarterly 17(3) 293-307.

Venkatesh, V., F.D. Davis. 1996. A model of the antecedents of perceived ease of use: development and test. Decision Sciences 27(3) 451-481.

Venkatesh, V., F.D. Davis. 2000. A theoretical extension of the technology acceptance model: four longitudinal field studies. Management Science 46(2) 186-204.

Venkatesh, V., M.G. Morris, G.B. Davis, F.D. Davis. 2003. User acceptance of information technology: toward a unified view. MIS Quarterly 27(3) 425-478.

Vicinanza, S.S., T. Mukhopadhyay, M.J. Prietula. 1991. Software-effort estimation: an exploratory study of expert performance. Information Systems Research 2(4) 243-262.

Webster, J., J.J. Martocchio. 1992. Microcomputer playfulness: development of a measure with workplace implications. MIS Quarterly 16(2) 201-226.

Wiedenbeck, S. 1985. Novice/expert differences in programming skills. International Journal of ManMachine Studies 23(4) 383-390.

Wood, S.L., J.G. Lynch Jr. 2002. Prior knowledge and complacency in new product learning. Journal of Consumer Research 29(3) 416-426.

Wu, J.-H., Y.-M. Wang. 2007. Measuring ERP success: the key-users' viewpoint of the ERP to produce a viable IS in the organization. Computers in Human Behavior 23(3) 1582-1596.

Yoon, Y., T. Guimaraes, Q. O'Neal. 1995. Exploring the factors associated with expert systems success. MIS Quarterly 19(1) 83-106.

Zhao, L., Y. Lu. 2012. Enhancing perceived interactivity through network externalities: an empirical study on micro-blogging service satisfaction and continuance intention. Decision Support Systems 53(4) 825-834. 
Zhou, T. 2013. An empirical examination of continuance intention of mobile payment services. Decision Support Systems 54(2) 1085-1091.

Zhou, Z., Y. Fang, D.R. Vogel, X.-L. Jin, X. Zhang. 2012. Attracted to or locked in? Predicting continuance intention in social virtual world services. Journal of Management Information Systems 29(1) 273-306. 


\section{Online Appendix}

\section{Quiz for IT-knowledge}

1. The ___ is used in combination with other keys to perform shortcuts and special tasks.
A) Control (Ctrl) key
C) Toggle key
B) Function key
D) Windows key

2. __ is the place in a computer where the programs and data the computer is currently using are stored.
A) RAM
B) ROM
C) The CPU
D) The power supply

3. Functions such as email exchange, web access and database access are built on the model.
A) client/server
B) peer to peer
C) token-ring
D) star

4. Which of the following is true?
A) both clients and server have OS
B) only server has OS
C) only client has OS
D) neither clients nor server requires OS

5. All computers on the Internet can act as
A) Clients or Servers
B) Clients
C) Servers
D) Neither- they're just hosts

6. Which of the following is NOT an example of a network node?
A) a mouse
B) a printer
C) a modem
D) a computer

7. A wireless network uses which of the following as its transmission medium?
A) radio waves
B) fiber-optic waves
C) sound waves
D) laser waves

8. __ networks do not require a dedicated server.
A) Peer-to-peer
B) Client/server
C) Intranet
D) Extranet

9. _ is a private computer network that interconnects remote (and often geographically separate) networks through primarily public communication infrastructures such as the Internet.
A) VPN
B) PCN
C) WAN
D) LAN

10. For viewing multimedia, and streaming video and audio, is the most widely used plugin in a web browser or on supported mobile devices. 

A) Adobe Flash Player
B) Windows Player
C) Youtube
D) Internet explorer

11. Because of the bandwidth efficiency and low costs, businesses are migrating from traditional copper-wire telephone systems to systems.
A) Voice over Internet Protocol
B) Public Switched Telephone Network
C) Virtual Private Network Protocol
Protocol
D) Wireless Fidelity Protocol

12. In cloud computing, where is the data handled?
A) On your computer
B) On your employer's servers
C) On third party servers
D) No servers are required

13. E-mail server deploys which of the following?
A) SMTP
B) FTP
C) HTTP
D) All of the above

14. Which of the following are good tips for creating an effective Subject Line for your email message?
A) Don't put everything in CAPS.
B) Don't overuse exclamation points
C) Avoid use of words such as Free,
D) All of the above
Discount, Call Now, or Save, or
Information you requested

15. In the URL http://www.wikipedia.org, the portion labeled http is the
A) protocol
B) domain name
C) host
D) top-level domain

16. A user, who has disabled Javascript, will not be able to properly use pages which are
A) Dynamic
B) made by Java
C) Static
D) Cached

17. Breadcrumbs, i.e. links to parent pages in a hierarchical site structure
A) often appear at top of a web page.
B) often appear at bottom of a web page
C) are only used by bank sites.
D) are not used because of security reasons.

18. Which of the following formats are used to exchange data between systems?
A) XML
B) JML
C) RML
D) FML

19. What is term or symbol used to search two words as an exact phrase in an exact order.
A) And
B) Or
C) Quotation marks
D) Parentheses

20. To show that the transmission of data between a user and company's website is secure, the 
following symbols are used.
A) Golden padlock
C) Security seal of certifying authority
B) https instead of http
D) All of the above

21. Which of the following statements is false about electronic calendars?
A) Allows you to block appointment time
B) Allows you to record your appointments slots in your client's calendar
C) Allows you to change your appointment
D) Automatically notifies and reminds you about

22. Which of the following is not true about screen sharing tools:
A) Enables asynchronous sharing of resources
B) Receive help with computer problems from anywhere.
C) Collaborate on programs with others.
D) Access files and folders on a computer from elsewhere.

23. Which of the following is not true about enterprise systems?
A) Enterprise software is expressly built to allow companies to mimic their unique business practices.
B) Enterprise systems help firms respond rapidly to customer requests for information or products.
C) Enterprise system data have standardized definitions and formats that are accepted by the entire organization.
D) Enterprise software includes analytical tools to evaluate overall organizational performance.

24. Customer relationship management systems typically provide software and online tools for sales, customer service, and:
A) marketing
B) account management
C) advertising
D) public relations

25. The largest software related expenditure for organizations is:
A) systems maintenance
B) project planning
C) implementation
D) requirements structuring

26. Which of the following is not a phase of systems development life cycle?
A) Prototyping
B) System analysis
C) System design
D) Implementation

27. When are the most expensive defects most likely to be introduced into a product?
A) When the product is being assembled
B) When the product is being designed
C) When the quality management plan is
D) When the product is being reviewed being written
by the customers.

28. __ helps teams respond to frequently changing software requirements through incremental, iterative work cadences.
A) Agile development
B) Waterfall development 

C) Prototyping
D) Flexible development

29. Which of the following is not an open source product?
A) Google
B) Firefox
C) Java
D) Wikipedia

30. Which of the following becomes increasingly important in a virtual team environment?
A) Communication planning
C) Formal procurements closure
B) Requirements engineering
D) Service level agreement

31. What is true for prototypes?
A) Prototyping causes significant costs and should be avoided wherever possible.
B) They are tangible and allow for early feedback on requirements by stakeholders.
C) Prototypes are mostly developed toward the end of a design or build phase.
D) Prototypes increase the risk of misunderstandings between developers and users.

32. Which of the following is a true statement regarding project time estimates?
A) Project time estimates for task completion
B) Resource estimates should not be and overall system quality are significantly influenced by the assignment of people to tasks. revised based upon the skills of the actual person assigned to a particular activity.
C) Staff learning can be enhanced by assigning
individuals to tasks that are "over their heads."
D) Project time estimates are always on target.

33. Hardware or software designed to guard against unauthorized access to a computer network is known as a(n)
A) firewall
B) hacker-proof program
C) hacker-resistant server
D) encryption safe wall

34. is a type of malware (malicious software) installed on computers that collects information about users without their knowledge.
A) Spyware
B) Phishing
C) Worm
D) Freeware

35. What is "phishing?"
A) "Spoofed" e-mails and fraudulent websites
B) A type of computer virus designed to fool recipients into divulging personal financial data such as credit card numbers, account usernames and passwords
C) An example of a strong password
D) None of the above

36. Which of the following is the strongest password:
A) \$jelF2bb
B) Administrator 

C) $\% 4 \mathrm{Btv}$
D) My dog's name

37. Almost $80 \%$ of the security lapses occur because of
A) Insider attacks
B) Spyware attacks
C) Viruses attacks
D) Hacking attacks

38. is the process of transforming information (referred to as plaintext) using an algorithm (called a cipher) to make it unreadable to anyone except those possessing special knowledge, usually referred to as a key.
A) Encryption
B) Hiding
C) Transforming
D) Coding

39. Free public Wi-Fi at a café is
A) not safe to do online banking because bank
B) completely safe to do online banking sites cannot enforce any security measure to ensure safe public Wi-Fi usage because bank sites are required to place appropriate measures for ensuring public Wi-Fi usage.
C) not safe to do online banking because bank D) completely safe to do online banking sites are not required to place appropriate measures for ensuring public Wi-Fi usage. because no extra security measures are required than what bank sites already have in place.

40. If your system is infected with a spyware then you could use a(n) to get rid of it.
A) anti-virus
B) patch
C) firewall
D) none of the above

41. What is the IT budget of your company? [options not provided because of the anonymity request of the participating company]

42. Which of the following correctly represents IT vision of your company? [options not provided because of the anonymity request of the participating company]

43. Which of the following information systems applications are not available in your company? [options not provided because of the anonymity request of the participating company]

44. What is the name of the head of the IT support in your company? [options not provided because of the anonymity request of the participating company]

45. Which of the following people can you contact within your company as a source of information about IT? [options not provided because of the anonymity request of the participating company]

46. Which of the following options can you use to access knowledge base such as FAQs of your company? [options not provided because of the anonymity request of the participating company] 